Marquette University

e-Publications@Marquette

Chemistry Faculty Research and Publications

Chemistry, Department of

$1-1-2012$

NMR Line Shapes and Multi-State Binding

Equilibria

Evgeni Kovrigin

Marquette University, evgueni.kovriguine@marquette.edu

Accepted version. Journal of Biomolecular NMR, Vol. 53, No. 3 (2012): 257-270. DOI: 10.1007/

s10858-012-9636-3. (C) 2012 Springer Verlag. Used with permission.

Shareable Link. Provided by the Springer Nature SharedIt content-sharing initiative. 


\title{
NMR Line Shapes and Multi-State Binding Equilibria
}

\author{
Evgenii L. Kovrigin \\ Department of Chemistry, Marquette University \\ Milwaukee, WI
}

\begin{abstract}
Biological function of proteins relies on conformational transitions and binding of specific ligands. Protein-ligand interactions are thermodynamically and kinetically coupled to conformational changes in protein structures as conceptualized by the models of pre-existing equilibria and induced fit. NMR spectroscopy is particularly sensitive to complex ligandbinding modes-NMR line-shape analysis can provide for thermodynamic and kinetic constants of ligand-binding equilibria with the site-specific resolution. However, broad use of line shape analysis is hampered by complexity of NMR line shapes in multi-state systems. To facilitate interpretation of such spectral patterns, I computationally explored systems where isomerization or dimerization of a protein (receptor) molecule is coupled to binding of a ligand. Through an extensive analysis of multiple exchange regimes for a family of three-state models, I identified signature features to guide an NMR experimentalist in recognizing specific interaction mechanisms. Results also show that distinct multistate models may produce very similar spectral patterns. I also discussed aggregation of a receptor as a possible source of spurious three-state line shapes and provided specific suggestions for complementary experiments that can ensure reliable mechanistic insight.
\end{abstract}

Keywords: NMR, line shape analysis, kinetics, exchange, ligand binding, proteins 
NOT THE PUBLISHED VERSION; this is the author's final, peer-reviewed manuscript. The published version may be accessed by following the link in the citation at the bottom of the page.

\section{Introduction}

The contemporary view of protein-ligand interaction mechanisms is based on concepts of conformational changes occurring in the binding partners (MWC model or "conformational selection" (Monod et al. 1965)) or in the bound complex ("induced fit", (Koshland 1958)) to modulate affinity of ligand binding and allow for regulatory interactions (Boehr et al. 2009; Csermely et al. 2010; Ma and Nussinov 2010). Conformational transitions in proteins serve as a mechanism to couple distant ligandbinding sites-as described by the concept of "allostery" (for reviews see (Swain and Gierasch 2006; Gunasekaran et al. 2004; Tsai et al. 2008)). These properties of protein molecules are crucial to operation of sophisticated regulation and signaling networks, yet are challenging to quantitatively address. A very significant effort in systems biology led to understanding that establishing accurate details of interactions on a molecular level is required for elucidating of complex cellular functions (Mogilner et al. 2006; Haugh et al. 2009).

Nuclear Magnetic Resonance (NMR) spectroscopy is an exquisitely powerful tool to detail biomolecular mechanisms (Boehr et al. 2009). In particular, analysis of NMR line shapes (Kaplan and Fraenkel 1980) enables accurate determination of kinetic and thermodynamic parameters at a site-specific resolution (for a review see (Rao 1989)). NMR line shape analysis has been successfully utilized to elucidate how protein-ligand interactions are coupled to internal conformational dynamics of the protein structures (for examples, see (Kern et al. 1995; Gunther et al. 2002; Mittag et al. 2003; Kovrigin and Loria 2006; Cogliati et al. 2010)). However, for molecular mechanisms with two or more coupled transitions, the line shape behavior might be very complex to analyze and is prone to misinterpretation in practice. Therefore, this precious information source remains largely unutilized.

To demonstrate the rich information content of line shapes in NMR titrations, I performed extensive NMR line-shape simulations for the three-state mechanisms where ligand binding is coupled to an isomerization or dimerization of a protein or a protein-ligand complex. A key goal of this paper is to survey the multi-state spectral patterns

Journal of Biomolecular NMR, Vol. 53, No. 3 (2012): pg. 257-270. DOI. This article is @ Springer and permission has been granted for this version to appear in e-Publications@Marquette. Springer does not grant permission for this article to be further copied/distributed or hosted elsewhere without the express permission from Springer. 
in NMR titrations to facilitate practical identification of the appropriate mechanistic models. I contrast the three-state NMR titration line shapes with those originating from the simplest two-state binding to reveal important distinguishing features among the various models. Through exhaustive analysis of various regimes of conformational exchange in basic three-state models, I determined specific conditions under which underlying molecular mechanisms may be unambiguously identified in NMR titrations, as well as those that require additional measurements. To simulate NMR line shapes in titration series for the purpose of this analysis, I developed a software package LineShapeKin Simulation (available from http://lineshapekin.net). This package may be used as a guide to a more efficient research design to predict NMR titration spectral series in a broad range of conditions.

Abbreviations: $\mathrm{R}-\mathrm{a}$ receptor; $\mathrm{L}-\mathrm{a}$ ligand; $\mathrm{C}_{\mathrm{R}}, \mathrm{C}_{\mathrm{L}}-$ total concentrations of $R$ and $L, m o l / L ; C_{L} / C_{R}-a$ molar ratio of $L$ and $R$ in the sample serving as a marker of the titration progress; $[X]-$ an equilibrium concentration of species $\mathrm{X}, \mathrm{mol} / \mathrm{L} ; \mathrm{K}_{\mathrm{a}}$-an equilibrium association constant for ligand binding; $\mathrm{K}_{\text {iso }}-$ an equilibrium constant for intramolecular isomerization of the receptor $\left(R \Leftrightarrow R^{*}\right)$; $K_{\text {dim }}-$ an equilibrium dimerization constant of the receptor $\left(R \Leftrightarrow R_{2}\right)$.

\section{Results and Discussion}

This paper is structured to contain five related subsections, as follows:

(1 and 2) Here, I reappraise the value of NMR line shape analysis for two-state binary binding processes. I emphasize that conventional analysis of peak shifts in titrations may be highly deceptive. I also highlight the information content of the NMR line shapes in the slow-exchange regime.

(3) A discussion of the impact of three-state equilibria on appearance of NMR titration series. I focus on distinctive features of the three-state systems as well as point out significant ambiguity of their spectral titration patterns-specifically, arising from selfassociation/aggregation of the ligand-free and ligand-bound

Journal of Biomolecular NMR, Vol. 53, No. 3 (2012): pg. 257-270. DOI. This article is @ Springer and permission has been granted for this version to appear in e-Publications@Marquette. Springer does not grant permission for this article to be further copied/distributed or hosted elsewhere without the express permission from Springer. 
receptor species. This underscores the need for a cautious approach to data interpretation.

(4) A case study of a very unusual observation from recent literature where, upon addition of substoichiometric ligand, protein NMR peaks were narrowed and intensified relative to the resonances from the unbound protein. Simulations revealed that such "anomalous transient narrowing" behavior is easily accounted for by an equilibrium three-state model. Such (previously anomalous) behavior may be expected in any complex systems with more than two states.

(5) A brief discussion of challenges in quantitative studies of the multistate exchange mechanisms and a need for integrative data analysis, in which multiple measurements from complementary experimental approaches including NMR and other biophysical techniques are analyzed simultaneously.

\section{The necessity of line-shape analysis: Lessons from the simplest mechanism, 1:1 binding}

Before focusing on analysis of NMR line shape titration patterns in the three-state systems, it is worth re-evaluating the simplified approach used in many studies of binding interactions. There, the titration progress is monitored by recording the progression of peak positions (frequencies). This is an approximation that assumes a normalized shift of the fast-exchange averaged peak ${ }^{1}$ to be a measure of fractional saturation of a bound complex. Several authors have noted (Markley 1975; Feeney et al. 1979; Sudmeier et al. 1980) that when the binding process enters the intermediate exchange regime, the approach is inadequate-the frequency of an average resonance ceases to be a dependable proxy for the fractional saturation. In that case, a resulting sigmoidal titration profile may be erroneously interpreted as a manifestation of cooperative binding (i.e., where the Hill coefficient is >1) (Markley 1975).

Fig. 1 demonstrates this issue with simulated titrations for the $1: 1$ binding mechanism, $R+L \Leftrightarrow R L$, in both fast-intermediate (Panels $A$ and $B$ ) and slow-intermediate (Panels $C$ and $D$ ) exchange regimes. The fast-intermediate case produces a curve of the averaged peak position versus $C_{L} / C_{R}$ (Panel $B$ ) proportional to an equilibrium concentration of 
the complex, $[R L]$. Therefore, this may be fit to obtain the binding constant. However, when the rate constant for ligand release $\left(k_{\text {off }}\right)$ is smaller than $\Delta \omega$ (Fig. 1, Panels $C$ and $D$ ), the titration series opens in the slow-exchange regime and gradually progresses through the intermediate and into the fast-exchange case. This occurs as the equilibrium concentration of $L$ increases and, correspondingly, the exchange rate constant is modified according to $k_{e x}=k_{\text {on }}[L]+k_{\text {off }}$. The transition from slow-intermediate to fast exchange causes the sigmoidal curvature of a peak progression in Fig. 1.D, which might be erroneously taken as an indication of cooperative binding of two ligand molecules. The line broadening in the middle of such titration series is remarkably severe, making it difficult to observe peaks at the intermediate points. Yet using cryogenic probes, modern experiments commonly have enough sensitivity to follow such peaks. The above analysis shows the corresponding care that must be taken with this new experimental power. Summarizing, it is advisable to abandon tracking peak positions altogether in favor of analysis of NMR line shapes of titration series using specialized software programs, such as MEXICO (Bain and Duns 1996), NMRKIN (Günther and Schaffhausen 2002; Cogliati et al. 2010), and LineShapeKin 3.2 (developed by the author and available from http://lineshapekin.net). It is also important to mention that to improve accuracy of the $K_{a}$ measurement it is advisable to increment the $C_{L} / C_{R}$ ratio in smaller steps in the nearequivalence region, which is most sensitive to variation of the binding constant.

\section{The surprising value of line-shape analysis in slow exchange}

Another underappreciated feature of NMR line shapes is that even in slow exchange, consideration of the full line shape is very informative. Panels $A$ and $C$ of Fig. 2 illustrate a case of $1: 1$, two-state binding in the slow-exchange regime. A remarkable feature of these spectral series-a textbook signature of slow exchange-is that the peaks do not move through the titration. The A panel demonstrates line shapes for weak (from a biochemical standpoint) binding with $K_{a}=$ $10^{5} \mathrm{M}^{-1}$, while the $C$ panel corresponds to a tight-binding event, $\mathrm{K}_{\mathrm{a}}=$ $10^{7} \mathrm{M}^{-1}$. In both cases, we observe a two-peak pattern with progressive redistribution of intensities towards the bound species, RL.

Journal of Biomolecular NMR, Vol. 53, No. 3 (2012): pg. 257-270. DOI. This article is @ Springer and permission has been granted for this version to appear in e-Publications@Marquette. Springer does not grant permission for this article to be further copied/distributed or hosted elsewhere without the express permission from Springer. 
Due to the absence of easily detectable peak shifts and apparently insignificant line broadening, slow-exchange NMR data are typically considered less useful for analysis of binding processes. Yet, Fig. 2 shows that line-shape titration series contain sufficient information to determine binding affinity. In the Fig. $2 \mathrm{~B}$ and $\mathrm{D}$, the line widths of the emerging $R L$ peak are plotted vs. titration progress (same $C_{L} / C_{R}$ values as in panels $A$ and $\mathrm{C}$ ). The RL resonance appears very broad and low intensity in early stage of the titration series and finally narrows to the line width of the pure $R L$ species upon saturation of $R$ with $L$. Comparing full-width-at-half-height (FWHH) profiles in panels $B$ and $D$, one notices a dramatic difference in the evolution of the line width for binding interactions of different affinity. This is the crux of the value of line-shape analysis in evaluating slow-exchange titrations. In simulations here, I intentionally used a number of small $C_{L} / C_{R}$ steps in vicinity of the equivalence point $C_{L} / C_{R}=1$ to highlight the difference between the two cases. However, it is not a routine practice to perform NMR titrations with such an accurate coverage of the nearequivalence region-another reason why slow-exchange NMR data are conventionally considered useless for analysis of binding parameters. Nonetheless, even more regular and sparse sampling of the binding process would have been sufficient to obviously distinguish the cases simulated here.

One alternative way of evaluating slow exchange NMR titrations is to use the peak intensities in slow exchange as approximating fractional saturation of the bound complex (for example, (Kempf et al. 2007)). The limitation in this case is that intensities follow fractional saturation only when exchange regime is extremely slow ensuring that resonances are not significantly broadened during the titration relatively to resonances of a ligand-free receptor or a fully saturated complex. If the peak areas (in 1D projections) or volumes (in 2D spectra) are evaluated instead of the intensities, then the fractional saturation is correctly estimated at all times and may be fit to obtain $\mathrm{K}_{\mathrm{a}}$. However, to evaluate a peak volume one has to fit the resonance envelope with a line shape function, which again amounts to a form of line shape analysis. Therefore, we conclude that NMR line-shape analysis should be used as a standard approach to achieve accurate interpretation of the slow-exchange binding data.

Journal of Biomolecular NMR, Vol. 53, No. 3 (2012): pg. 257-270. DOI. This article is @ Springer and permission has been granted for this version to appear in e-Publications@Marquette. Springer does not grant permission for this article to be further copied/distributed or hosted elsewhere without the express permission from Springer. 


\section{Three-State Mechanisms and NMR Titration Series}

Fig. 3 shows a set of the elementary three-state models employed in the current analysis. The ' $R$ ' denotes an isotopically labeled species (the "receptor" and NMR reporter), and the 'L' stands for the unlabeled binding partner (the "ligand"). The $R$ and $L$ labels should not be taken as indicating the size and the nature of the molecules, and are only used to track incorporation of the NMR-active nucleus. I also denote the ligand-binding transition as process ' $A$ ', and the coupled isomerization/dimerization as process ' $B$ ' regardless of mechanistic details. The basic binary binding mechanism ("lock-andkey" (Fischer 1894)) is denoted as a U model, and corresponds to $1: 1$ binding cases discussed in the preceding subsections. The $U-R$ and $U-L$ models include the pre-existing intramolecular conformational isomerization of $\mathrm{R}$ or $\mathrm{L}$ to $\mathrm{R} *$ or $\mathrm{L}^{*}$, thus representing conformational selection mechanisms (Monod et al. 1965; Kumar et al. 2000; Gunasekaran et al. 2004). In this case the B process is presumed competitive with binding, i.e., $\mathrm{R}^{*}$ or $\mathrm{L}^{*}$ are incapable of complex formation. These models include a very common and important threestate scenario-the ligand binding coupled to protein foldingdemonstrated by hydrogen exchange analysis (for example, (Henkels et al. 2001)) and NMR spin-relaxation methods (Sugase et al. 2007a). The models $U-R 2$ and $U-L 2$ describe dimerization equilibria in which dimers are likewise incapable of binding. The U-RL model is the classical induced-fit mechanism (Koshland 1958, 1994). In the model $\mathrm{U}-\mathrm{R} 2 \mathrm{~L} 2$, a dimerization interface is revealed only in the bound complex with the $R$ and $L$ species incapable of dissociating from the $R L$ dimer. Consideration of these elementary three-state mechanisms serves as the first step towards treatment of more complex coupled equilibria. Finally, a selection of molecular models with greater than three exchanging species are shown in the Supplementary Fig. 1 and are also included in LineShapeKin Simulation.

In NMR experiments the samples typically contain proteins at non-physiologically high concentrations (up to millimolar), therefore self-association/aggregation represents a common source of experimental artifacts. It is a routinely necessary control to perform measurements at different sample concentrations in order to test for

Journal of Biomolecular NMR, Vol. 53, No. 3 (2012): pg. 257-270. DOI. This article is @ Springer and permission has been granted for this version to appear in e-Publications@Marquette. Springer does not grant permission for this article to be further copied/distributed or hosted elsewhere without the express permission from Springer. 
aggregation, but the question remains: how little aggregation may still produce spurious response in NMR line-shape series? The U-R2, U-L2 and U-R2L2 models may serve to explicitly account for these common sources of artifacts, given that a dimer formation is the first step in non-specific aggregation blocking ligand binding or dissociation.

The three-state mechanisms shown in Fig. 3 are capable of producing a variety of NMR line shape titration patterns. This is due to multiple possible combinations of different exchange regimes in the coupled transitions $A$ and $B$. By inspecting a large number of simulation results, I have identified several recognizable patterns that may be observed in NMR titration experiments.

\section{Fast-Exchange Regime}

When both binding and isomerization/dimerization processes in the system are in the fast-exchange limit $\left(k_{e x}>\Delta \omega\right)$, the line shapes in the titration are represented by a single peak moving from the initial to the final positions as shown in Fig. 4. In this figure I simulated twoand three-state system in such a way that starting and ending peaks appear in the same places in all panels to facilitate comparison of the line shape patterns. For a reference, a titration series for the binary $U$ model in fast exchange is shown in the panel $A$ with $K_{a}(A)=10^{6} \mathrm{M}^{-1}$, and $k_{-1}(A)=1000 \mathrm{~s}^{-1}$. Panels $B$ and $C$ demonstrate that addition of fast-exchange isomerization or dimerization equilibria $\left(k_{-1}(B)=1000 \mathrm{~s}^{-}\right.$ ${ }^{1}$ ) to the "front end" of the binding reaction produces increased line broadening, which is typically associated with the exchange regime shifting away from the fast-exchange limit. This observation is surprising because the frequency difference between $R$ and $R L$ in these simulations is actually reduced so the exchange regime in the binding transition, nominally, becomes faster. Line widths of peaks for $\mathrm{U}-\mathrm{R}$ and $\mathrm{U}-\mathrm{R} 2$ simulations are plotted in the panel $\mathrm{F}$ for comparison to the $U$ model. It is also notable that the maximum line broadening in the titration series is observed at higher $C_{L} / C_{R}$ values in presence of a coupled fast-exchange process than in the $U$ model. This shift increases when the exchange kinetics in the coupled process becomes slower (simulations not shown).

Journal of Biomolecular NMR, Vol. 53, No. 3 (2012): pg. 257-270. DOI. This article is @ Springer and permission has been granted for this version to appear in e-Publications@Marquette. Springer does not grant permission for this article to be further copied/distributed or hosted elsewhere without the express permission from Springer. 
Addition of the isomerization or dimerization equilibrium in fast exchange to the "back end" of the binding reaction leads to even more dramatic line broadening (panels $D$ and $E, U-R L$ and UR2L2, respectively). Again, despite the reduced $\Delta \omega$ between $\mathrm{R}$ and $\mathrm{RL}$ making binding transition to occur in even faster exchange regime, the titration series appears to be in an intermediate exchange deceptively suggesting significantly slower kinetics than in the $U$ model in panel $A$. The dramatic line broadening of $U-R L$ and $U-R 2 L 2$ titrations is shown in the panel $\mathrm{F}$.

Addition of isomerization/dimerization of a free ligand creates the $U-L$ and $U-L 2$ models, which are unique in that they involve a coupled process $B$ in the unobservable species. As a consequence, irrespective of the exchange regime in process $B$, the $U-L$ and $U-L 2$ will retain the fast-exchange appearance of the $U$ model (simulations not shown). However, reversal of the labeling pattern (that is incorporating the NMR-active nucleus into $L$ instead of $R$ ) effectively converts these models to $U-R$ and $U-R 2$, and the effect of coupled equilibrium becomes detectable. The exchange regime in the reverse titration may change because chemical shift differences are generally uncorrelated between nuclear spins of the receptor and the ligand. Line shapes from such "forward" and "reverse" titrations should be analyzed simultaneously to resolve parameters of the individual transitions (for example, see (Greenwood et al. 2011)). Reversing labeling between the receptor and the ligand, being a quite common approach in NMR studies of molecular interactions, thus is also recommended in NMR line shape analysis of multi-state binding mechanisms.

The U-R2 and U-R2L2 models have another distinctive feature that they reveal concentration-dependent spectra due to otherwise hidden fast-exchange dimerization processes. In particular, the frequency of an initial peak in the titration series of the U-R2 mechanism (and a final peak in the U-R2L2) is dependent on the total concentration of $\mathrm{R}$. When NMR sample is prepared with different concentration of a receptor, a population balance in the dimerization equilibrium will be altered resulting in a shift of the weighted-average peak.

Journal of Biomolecular NMR, Vol. 53, No. 3 (2012): pg. 257-270. DOI. This article is @ Springer and permission has been granted for this version to appear in e-Publications@Marquette. Springer does not grant permission for this article to be further copied/distributed or hosted elsewhere without the express permission from Springer. 
NOT THE PUBLISHED VERSION; this is the author's final, peer-reviewed manuscript. The published version may be accessed by following the link in the citation at the bottom of the page.

A complementary NMR approach capable of detecting equilibria occurring in the absence of a ligand ( $U-R$ and $U-R 2)$ or upon complete saturation of the receptor ( $U-R L$ and $U-R 2 L 2)$ is a relaxation dispersion measurement (Palmer et al. 2001; Kay 2005). Analysis of relaxation dispersions in the three-state systems has been successfully demonstrated (Grey et al. 2003; Sugase et al. 2007b; Korzhnev et al. 2009). Global analysis of NMR line shapes and relaxation dispersions seems to be a powerful approach to the identification of a correct molecular mechanism of the multi-state exchange.

\section{Slow-Exchange Regime}

If both $A$ and $B$ processes are in slow exchange with significant populations in the $B$ process, then identification of a three-state model may be straightforward: the U-R and U-R2 models will show two peaks disappearing upon titration with one appearing at a frequency of the bound species; the pattern due to U-RL and U-R2L2 will be reversed. In case of dimerization, the line widths the two peaks will be different as the rotational correlation time of a dimer is increased relatively to the monomer, resulting in a larger line width (Abraham 1983). However, isomerization may also lead to slower rotational diffusion (for example, upon transition between spherical and elongated shapes) therefore mere difference in the line width is not sufficient to recognize the U-R2 or U-R2L2. Also, it is noteworthy that for large ligands (e.g., a protein or a nucleic acid) the size increase on binding can dramatically broaden spectral lines and diminish signal-to-noise ratio towards the end of a titration series. In that case, doubling of emerging peaks due to $\mathrm{U}-\mathrm{RL}$ or $\mathrm{U}-\mathrm{R} 2 \mathrm{~L} 2$ models is less likely to be observed, especially if populations are skewed. Similarly, the models with the coupled process B occurring in the NMR-silent ligand, $U-L$ and U-L2, will produce a standard 'two-state' slow-exchange titration pattern (as in Fig. 2) for any exchange regime in B.

When doubling of the peaks in the initial or final states is observed, the models with dimerization/oligomerization (U-R2 and UR2L2) may be distinguished from the models with intramolecular conformational change ( $U-R$ and $U-R L$ ) by evaluating how a ratio between the peak areas (volumes) of a monomer and a dimer changes upon the titration progress or dilution. The basis of the distinction is

Journal of Biomolecular NMR, Vol. 53, No. 3 (2012): pg. 257-270. DOI. This article is @ Springer and permission has been granted for this version to appear in e-Publications@Marquette. Springer does not grant permission for this article to be further copied/distributed or hosted elsewhere without the express permission from Springer. 
that the monomer-dimer ratio is dependent on the total receptor concentration while isomerization equilibria are concentrationindependent. For example, in the U-R2 mechanism, the concentration of a free receptor progressively decreases upon ligand addition thus driving dimerization equilibrium towards monomeric species (equivalent to dilution in absence of a ligand). Therefore, the ratio between peak areas of $\mathrm{R}$ and $\mathrm{R}_{2}$ species will increase upon titration progress because of relative depopulation of $\mathrm{R}_{2}$. In contrast, intramolecular isomerization in the $\mathrm{U}-\mathrm{R}$ mechanism is independent of concentrations rendering ratio between areas of $\mathrm{R}$ and $\mathrm{R} *$ constant. For similar reasons, in the U-R2L2 mechanism, the ratio between peak areas of $(R L)_{2}$ and $R L$ will increase upon titration progress due to accumulation of the bound receptor leading to a shift of the dimerization equilibrium towards $(R L)_{2}$. In contrast to U-R2L2, the ratio of peak areas for bound forms in U-RL will be constant throughout the entire titration. The most straightforward way to identify the U-R2 model is to collect a series of spectra while diluting the receptor sample in the absence of a ligand-redistribution of peak areas in favor of a monomer should be observed. Similarly, U-R2L2 model will show redistribution of peak areas upon diluting the receptor saturated with a ligand.

\section{Mixed exchange regimes}

In this subsection, I discuss cases when processes $A$ and $B$ are in opposite exchange regimes to illustrate unique spectral features and ambiguities of such titration series. Fig. 5 shows the variety of spectral titration patterns from three-state mechanisms in mixed exchange regimes. At the top, panels $a, b$ and $c$ illustrate aspects of the U-R mechanism, where a free receptor isomerizes into a non-binding $\left(R^{*}\right)$ species. This represents the popular 'conformational selection' model of protein-ligand interactions (Monod et al. 1965; Kumar et al. 2000; Gunasekaran et al. 2004). Fig. 5.a plots populations of species as they evolve upon addition of a ligand to the receptor sample. The plot is valid whether the $A$ and $B$ processes are fast and slow, or vice versa. An equilibrium constant for the $B$ transition was set to $K_{\text {iso }}(B)=5$ so the formation of $\mathrm{R}^{*}$ is favored in the free receptor (for specific simulation parameters see Methods section).

Journal of Biomolecular NMR, Vol. 53, No. 3 (2012): pg. 257-270. DOI. This article is @ Springer and permission has been granted for this version to appear in e-Publications@Marquette. Springer does not grant permission for this article to be further copied/distributed or hosted elsewhere without the express permission from Springer. 
Fig. 5.b shows a spectral titration series for $U-R$ with the $A$ process (ligand binding) in fast exchange and B process (isomerization) in the slow-exchange regime. The bottom (starting) trace in Fig. 5.b is a line shape of a free receptor. As expected for slow exchange with highly skewed populations, this yields a peak at $\mathrm{R}^{*}$ frequency, while the $R$ peak is of small intensity and additionally broadened relatively to the major $\mathrm{R}^{*}$ peak, therefore may be unobservable at practical signal-to-noise ratios (Kaplan and Fraenkel 1980; Cavanaugh et al. 2006). As the titration progresses, the $\mathrm{R}^{*}$ peak steadily diminishes remaining at the same frequency while the second peak grows between $R$ and $R L$ frequencies. The new peak is a fast-exchange weighted-average peak reflecting the relative populations of $\mathrm{R}$ and $\mathrm{RL}$. As the RL complex accumulates, the fastexchange peak becomes more intense and shifts from the $\mathrm{R}$ frequency towards the RL frequency. It may seem from this analysis that conformational selection with fast binding and slow isomerization can thus be easily recognized by noted signature features. However, as discussed ahead, that 'signature' is common to other molecular mechanisms (e.g., U-R2) ${ }^{2}$.

When swapping the exchange regimes are of $A$ and $B$ processes in the U-R model (Fig. 5.C), the titration appears as a classical slowexchange process giving no hint of the underlying three-state exchange. The reason for such 'simplicity' is that the isomerization transition between $\mathrm{R}$ and $\mathrm{R} *$-now in fast exchange-produces a population-weighted average peak positioned between $R$ and $R^{*}$. When the ligand is added, slow-exchange binding leads to a new growing peak at the RL frequency, with corresponding diminishing amplitude of the $\mathrm{R} / \mathrm{R}^{*}$ weighted-average peak. The position of the latter does not shift because ratio of $\mathrm{R}$ and $\mathrm{R}^{*}$ remains constant. ${ }^{3}$

The U-R2 model reflects a dimerization process, which prevents ligand binding. Corresponding NMR titration series are represented by simulations of Fig. 5.d, e, and f. Fast-exchange ligand binding combined with slow-exchange dimerization is represented in Panel e. This is capable of producing a titration pattern very similar to that of the U-R model in Fig. 5.b. Given their similarity, one has to be extremely cautious about possible oligomerization of the receptor in the NMR sample. The key handle for distinguishing between $\mathrm{U}-\mathrm{R}$ or $\mathrm{U}$ -

Journal of Biomolecular NMR, Vol. 53, No. 3 (2012): pg. 257-270. DOI. This article is @ Springer and permission has been granted for this version to appear in e-Publications@Marquette. Springer does not grant permission for this article to be further copied/distributed or hosted elsewhere without the express permission from Springer. 
$\mathrm{R} 2$ attributions to data series like Fig. $5 \mathrm{~b}$ and $\mathrm{e}$ is that equilibrium $R \leftrightarrow R_{2}$ is dependent on the starting $[R]$, while isomerization $R \leftrightarrow R^{*}$ is not. Thus, collecting spectra for a dilution series of the ligand-free receptor or a repeated titration at a different receptor concentration is needed for accurate assessment of the underlying mechanism. The line width of a dimer peak is also expected increase relatively to the one of the monomer due to doubling of the molecular weight. If the ligand is a small molecule then the line width of the saturated RL peak will be smaller than that of the initial R2 resonance-a feature easy to spot. However, for ligands with larger molecular weights (a protein or large peptide) the RL's line width will also be increased so quantitative line shape analysis is required for adequate interpretation of the data.

When the U-R2 exchange regimes are swapped to have slow binding and fast dimerization processes, another peculiar spectral feature can occur. Fig. 5.f reveals an initial peak that shifts and disappears while that for the bound complex grows in as a fixedposition, slow-exchange resonance. The shift of the fast-exchange peak of a free receptor occurs due a change of the ratio between relative populations of a receptor monomer and a dimer upon titration progress. As more and more $\mathrm{R}$ is sequestered in the $\mathrm{RL}$ form, the concentration of a free receptor drops, shifting the dimerization equilibrium towards a monomer. This explains the corresponding movement of the population-weighted $R / R_{2}$ resonance upon addition of a ligand. A range of other biophysical measurements may be also performed to detect dimerization/oligomerization in the ligand-free receptor such as ultracentrifugation (Gabrielson and Arthur 2011; Ortega et al. 2011), measurements of fluorescence depolarization (Royer and Scarlata 2008; Shepherd and Fuentes 2011), light scattering and other. Exchange dynamics between a monomer and a dimer as well as intramolecular isomerization in absence of a ligand may be readily detected using relaxation dispersion measurements (Palmer et al. 2001; Kay 2005) or longitudinal magnetization transfer (Farrow et al. 1994)-the experiments naturally complementing line shape analysis in multi-state systems.

The U-RL model is Koshland's famous induced-fit mechanism (Koshland 1958), where the bound complex rearranges into a more tightly bound species. In Fig. 5.g, this is reflected in the populations of

Journal of Biomolecular NMR, Vol. 53, No. 3 (2012): pg. 257-270. DOI. This article is @ Springer and permission has been granted for this version to appear in e-Publications@Marquette. Springer does not grant permission for this article to be further copied/distributed or hosted elsewhere without the express permission from Springer. 
the bound forms, where the formation of $R^{*} L$ is favored $\left(K_{\text {iso }}=5\right)$. When the induced fit (B process) is in fast exchange with slow ligand binding, the slow-exchange two-peak pattern of Fig. 5.h results. The $R L$ and $R * L$ forms behave spectrally as if they were a single species: providing a fast-exchange, weighted-average resonance that increases in intensity as $\mathrm{R}$ saturates with $\mathrm{L}$. Reversing exchange regimes such that binding is in fast exchange and induced-fit isomerization is slow, yields the spectral pattern of Fig. 5.i. This features an initial resonance that disappears and shifts while the final peak appears with gradually increasing intensity and fixed position due to its slow-exchange origins. Due to skewed populations of RL vs. $R^{*} \mathrm{~L}$ (the latter is favored $5: 1$ here), the small RL peak may be unobservable at practical signalto-noise ratios. Thus, this spectral series (Fig. 5.i) is notably similar to U-R2 under the conditions of Fig. 5.f. Therefore, fast-exchange oligomerization of the free receptor (e.g., due to high NMR sample concentrations) can give false appearance of the [scientifically more exciting] induced-fit interaction mechanism. Acquiring spectra of a dilution series of the receptor will reveal dependence of the frequency of the receptor resonance in $U-R 2$ while, in $U-R L$ model, the frequency of a free receptor will be concentration-independent.

Further highlighting ambiguity of the spectral appearances, panels $k$ and $I$ of Fig. 5 demonstrate how the U-R2L2 model (dimerization of the bound species) may produce spectral series matching those for both conformational selection, (U-R, Fig. 5.b similar to Fig. 5.k) and for induced fit (U-RL, Fig. 5.i similar to Fig. 5.I).

The major conclusion of this section is that the biologically 'exciting' models of the induced fit and conformational selection (U-R and $U-R L$ ) must always be tested against their counterparts involving dimerization (U-R2 and U-R2L2) or oligomerization blocking the ligandbinding site. Formation of $R_{2}$ or $(R L)_{2}$ dimers may be biologically important, yet may also arise as a widespread experimental artifact due to high concentrations of protein samples required for NMR experiments. As was noted above, dimerization/oligomerization equilibria are dependent on the sample concentration. Therefore, NMR titrations series at two different receptor concentrations should be sufficient to distinguish among the alternative mechanisms. Because NMR is relatively insensitive technique, one does not often have a 
freedom to significantly vary sample concentration. However, simulations indicate that if the $1 \mathrm{mM} N M R$ sample in the U-R2 model shown in Fig. 5.f is diluted 8 to16-fold, one would observe a frequency shift of the starting resonance on the order of $30 \mathrm{~s}^{-1}(4.8 \mathrm{~Hz})$.

Similarly, in cases of slow exchange dimerization/oligomerization, the concentration dependence of volumes (or peak areas) of the major and minor resonances of ligand-free (in U-R2) or ligand-saturated (in UR2L2) species should be examined. To support accurate assignment of the multi-state molecular mechanism, the complementary biophysical measurements to detect dimerization/oligomerization should also be performed.

\section{The Case Study: Anomalous Transient Narrowing}

In 2004, Mittag and colleagues reported an extremely curious observation made in ligand binding analysis of the $\mathrm{N}$-terminal src homology 2 domain ( $\mathrm{N}-\mathrm{SH} 2$ ) of phosphatidylinositide-3-kinase (Mittag et al. 2004). Out of 68 titration-responsive residues, they observed that the initial addition of a peptide ligand produced unusual spectral changes in 38 peaks. In particular, resonances became narrower and more intense upon early additions of the ligand than in the spectrum of the free protein. Figure 5.C in the manuscript by Mittag, et al. (Mittag et al. 2004) is reproduced here as Fig. 6.A (note that the $x-$ axis ordering is reversed in the figure relative to an NMR convention). The careful experimental protocol employed by the authors excluded possibility of jumps in the $\mathrm{pH}$ or salt concentration. The authors characterized the noted observation as, '...line shapes reflecting a simple one-step binding reaction starting not from the signal of the free $\mathrm{N}-\mathrm{SH} 2$, but rather starting from the second spectrum of the titration series.' [(Mittag et al. 2004), p.9020]. To explain increased intensity of a receptor peak after the first addition of a ligand, the authors proposed that a peptide ligand induced some sort of irreversible isomerization in $\mathrm{N}-\mathrm{SH} 2$ protein, which did not involve direct ligand binding. They emphasized that "...less than 0.1 equiv of PDGFr peptide is required for the [complete-ELK] conversion while the overall stoichiometry of the interaction remains $1: 1$." The mechanism proposed by the authors thus describes, essentially, an unexpected catalytic action of a peptide on conformation of a protein.

Journal of Biomolecular NMR, Vol. 53, No. 3 (2012): pg. 257-270. DOI. This article is @ Springer and permission has been granted for this version to appear in e-Publications@Marquette. Springer does not grant permission for this article to be further copied/distributed or hosted elsewhere without the express permission from Springer. 
However, here I present an alternative analysis that shows no need to invoke such complex assumptions in order to explain this unusual 'transient narrowing' of the line shapes. The apparent anomaly is readily attributable to a fully reversible three-state equilibrium in a mixed fast/intermediate exchange regime. Fig. 6.B shows simulated line shapes from the U-R mechanism. These demonstrate a weightedaverage fast-exchange peak that experiences transient narrowing upon initial addition of a ligand. This remarkable effect is a signature of a combination of specific conditions: (1) fast-exchange ligand binding, (2) intermediate-exchange isomerization of the free receptor, and (3) a receptor isomer $\left(R^{*}\right)$, which does not bind $L$, exhibits NMR frequency between the free $(R)$ and bound $(R L)$ receptor frequencies. In Fig. 6. $\mathrm{B}$, the third condition is clearly denoted by markers for the frequencies of pure species $\left(R, R^{*}\right.$ and $\left.R L\right)$, while the two noted criteria for process rates are also fixed as underlying parameters of simulation. Under these specific conditions, the initial peak is broadened by the intermediate-exchange process $\left(R \leftrightarrow R^{*}\right)$ natural to the free protein. With addition of the binding partner, the observed peak narrows and intensifies as it crosses the frequency of the nonbinding receptor species. Qualitatively, the transient narrowing may be understood by thinking of the whole scheme as a pseudo two-site exchange process. In this way, the $R \Leftrightarrow R L$ equilibrium represents a "single species" that is in intermediate exchange with $\mathrm{R}^{*}$. As the weighted-average "R $\Leftrightarrow R L$ " peak crosses the $R^{*}$ position, the frequency difference between these "species" vanishes, thus removing line broadening caused by the intermediate, pseudo-two-state exchange process.

Beyond the $\mathrm{U}-\mathrm{R}$ model, it is also possible to predict transiently narrowed line shapes from the other multi-state mechanisms treated in this manuscript. Indeed, by setting model parameters in the UR2, $\mathrm{U}-\mathrm{RL}$, and $\mathrm{U}-\mathrm{R} 2 \mathrm{~L} 2$ models to satisfy the three noted conditions, simulated titration series reveal the transient narrowing at various stages. For U-R2, the effect occurs in the beginning of a titration (Fig. 6C), whereas U-RL and U-R2L2 produce late-stage narrowing (URL-Fig. 6D; U-R2L2-Supplementary Information, Simulations/transient-narrowing). More extensive analysis of the physical background and investigation of the range of conditions that

Journal of Biomolecular NMR, Vol. 53, No. 3 (2012): pg. 257-270. DOI. This article is @ Springer and permission has been granted for this version to appear in e-Publications@Marquette. Springer does not grant permission for this article to be further copied/distributed or hosted elsewhere without the express permission from Springer. 
may produce this transient-narrowing phenomenon are outside of the scope of this paper.

The above discussion emphasized specific conditions for transient narrowing to occur in the three-state mechanisms, and one could expect that this phenomenon is not unique to the exchange between only three states. We can create conditions for transient narrowing in the four-state system if we add the coupled equilibria in the intermediate-exchange regime to the 'front' and 'back' ends of the binding reaction. The Fig. 7.A illustrates a reaction mechanism including non-binding $\mathrm{R}^{*}$ species as well as non-dissociating $(\mathrm{RL})^{* *}$ species. In practice, both processes may be related to conformational changes in a protein resulting in burial of the ligand-binding site (with or without a bound ligand). If both isomerization transitions occur in the intermediate exchange regime, while ligand binding is in fast exchange, and frequencies of $\mathrm{R} *$ and $(\mathrm{RL}) * *$ are between the frequencies for $\mathrm{R}$ and $\mathrm{RL}$, the spectral pattern with two transiently narrowed regions may result (Fig. 7.B). In a different scenario, the four-state system with isomerization on both ends may also be represented by Fig. 7.C reaction scheme, where $\mathrm{R}^{*}$ and $\mathrm{R} * \mathrm{~L}$ may directly interconvert. It may be a case when isomerization in a protein produces two alternative structures that both bind the ligand. In the most simple case when $L$ binds to $R$ and $R^{*}$ with equal affinity in fast exchange and both isomerization processes occur in intermediate exchange the spectral pattern Fig. 7.D may be observed.

The critical factor to observe the transient narrowing experimentally is that all three conditions-the intermediate exchange regime in the $B$ processes, intermediate frequencies for the isomers/dimers, and fast exchange for the ligand-binding processshould be met at the same time, which makes it not so likely for these unique spectral patterns to occur in practice. With broader application of the NMR line shape analysis in protein-ligand interaction studies, the experimentalist should be aware of these unusual spectral phenomena so not to discard such data as a result of suspected artifacts but utilize the information content instead. It is also not inconceivable that the transient narrowing phenomenon may be employed in selected systems to increase sensitivity of NMR experiments by reducing granted for this version to appear in e-Publications@Marquette. Springer does not grant permission for this article to be further copied/distributed or hosted elsewhere without the express permission from Springer 
excessive line broadening caused by the intermediate exchange phenomena in free and bound species.

\section{Data analysis in multi-state systems}

The simulations of NMR line shapes with multiple states in dynamic equilibrium such as presented in this paper may be performed with the LineShapeKin Simulation software for educational and instructional purposes. Practical analysis (fitting) of experimental NMR line shapes is enabled by the software programs NMRKIN published by Ulrich Günther (Cogliati et al. 2010; Günther and Schaffhausen 2002) and the NMR line shape module of IDAP software developed by the author (see below).

With growing number of states in exchange it becomes increasingly challenging to discriminate the possible alternative mechanisms on the basis of NMR line shapes alone. One solution is to make additional experimental measurements in order to illuminate the molecular mechanism from different complementary angles and enable building of an accurate multi-state model. Indeed, multiple experimental approaches were successfully utilized to provide complementary data when interrogating complex biomolecular systems in practice (for examples see (Sugase et al. 2007a; Korzhnev et al. 2009; Farber et al. 2010; Demers and Mittermaier 2009)). However, such integration of data from multiple complementary techniques requires sophisticated computer codes designed to simultaneously fit NMR line shapes in combination with results of other measurements while using various multi-state models.

To facilitate such analysis of complex biomolecular mechanisms, the author's laboratory is developing the Integrative Data Analysis Platform (IDAP), a versatile software program for global fitting of data from NMR titrations, ZZ-exchange experiments, CPMG relaxation dispersion measurements as well as stopped-flow transient kinetics, enzyme assays, Isothermal Titration Calorimetry (ITC), Surface Plasmon Resonance (SPR) and other sensitive biophysical and biochemical approaches (manuscript in preparation). The code of IDAP is available from the author upon request. 
NOT THE PUBLISHED VERSION; this is the author's final, peer-reviewed manuscript. The published version may be accessed by following the link in the citation at the bottom of the page.

\section{Conclusions}

The general theme of this paper is a discussion of NMR line shapes as a rich information source about multi-state molecular mechanisms of protein-ligand interactions. I am emphasizing how deceptive may be a simplified treatment of the spectral titrations, when only a peak shift is analyzed. The simulations of the three-state systems demonstrate unique features and inherent ambiguity of their spectral appearances thus requiring a quantitative line shape analysis to be performed. A number of cases is highlighted when very mechanistically different alternative models may account for the experimental data equally well. As an example of a practical application, the anomalous line shapes reported in the literature were found to originate from a simple three-state model, and a capacity of all multi-state models to create highly unusual spectral patterns was emphasized. All the discussed aspects of NMR spectra in multi-state systems strongly endorse the NMR line shape analysis as a must-have approach for a protein NMR practitioner.

\section{Methods}

\section{Theory}

The simultaneous thermodynamic equations relating total and equilibrium concentration of the ligand and receptor as well as all association/formation constants were written and solved symbolically or numerically using MuPad (MathWorks). The MuPad notebooks with derivations are available from the author upon request.

The line shapes of NMR signals from the receptor species during titration with ligand were simulated utilizing the Bloch-McConnell equations (McConnell 1958). In brief, Bloch equations for motion of the transverse magnetization in the rotating frame modified by McConnell (McConnell 1958) for chemical exchange take the form (Kaplan and Fraenkel 1980; Rao 1989):

$$
\frac{d M^{+}(t)}{d t}=(i \Omega-R+K) M^{+}(t)
$$

Journal of Biomolecular NMR, Vol. 53, No. 3 (2012): pg. 257-270. DOI. This article is @ Springer and permission has been granted for this version to appear in e-Publications@Marquette. Springer does not grant permission for this article to be further copied/distributed or hosted elsewhere without the express permission from Springer. 
where $M$ is the transverse magnetization vector for the spin in all species, $\Omega$ is a diagonal matrix of their Larmor frequencies in the rotating frame, $R$ is a diagonal matrix of their transverse relaxation rate constants, and $K$ is the matrix of coefficients of simultaneous rate equations for the mechanism. Intensity of the frequency-domain spectrum is proportional to a total magnetization and may be obtained for the steady-state reaction conditions from:

$$
I(v) \propto \operatorname{Re}\left[[1,1](i(\Omega-v)-R+K)^{-1} P\right],
$$

where $\mathrm{P}$ is a column vector of normalized concentrations of species containing the observed spin and $v$ is a spectral frequency.

The LineShapeKin Simulation software has been developed to perform simulations of NMR line shapes in titrations with complex multi-state mechanisms. The software code, comprehensive description and tutorials as well as a simple web interface are available from the author's website at http://lineshapekin.net/LineShapeKin Simulation 4.1/index.htm.

\section{Simulation parameters for multi-state models}

The LineShapeKin Simulation 4.1 software was used to perform all line shape simulations in this work. Specific simulation parameters utilized to create the figures in this paper are given in the figure legends or-if very extensive-in the following subsections.

Fig. 5-Mixed exchange regime in three-state systems

The equilibrium and rate constants used in the simulation are listed below. Transverse relaxation rate constants of pure species were set to $10 \mathrm{~s}^{-1}$. Total receptor concentration was set to $1 \mathrm{mM}$. The following $C_{L} / C_{R}$ values were utilized: $0,0.1,0.2,0.3,0.4,0.5,0.6$, $0.7,0.8,0.9,1.0,1.1,1.2$. The parameter file names for each simulation are shown in parentheses. The parameter files, additional plots of chemical shift changes and line widths are given in Supplementary Information, Simulation/Mixed_exchange. 
U-R model. $\mathrm{Ka}(\mathrm{A})=10^{6} \mathrm{M}^{-1}, \mathrm{~K}_{\text {iso }}(\mathrm{B})=5$; (Fig. 5.b) the transition $\mathrm{A}$ is in fast exchange, $B$-in slow: $k_{-1}(A)=1000 \mathrm{~s}^{-1}, k_{-1}(B)=1 \mathrm{~s}^{-1}$ (U_R_1.txt); (Fig. 5.C) the transition $A$ is in slow exchange, $B$-in fast: $k_{-1}(A)=1 \mathrm{~s}^{-1}$, $\mathrm{k}_{-1}(\mathrm{~B})=1000 \mathrm{~s}^{-1}\left(\mathrm{U} \_\mathrm{R} \_2 . \mathrm{txt}\right)$;

U-R2 model. $\mathrm{K}_{a}(A)=10^{6} \mathrm{M}^{-1}, \mathrm{~K}_{a}(B)=10^{4} \mathrm{M}^{-1}$; (Fig. 5.e) the transition $A$ is in fast exchange, $B$-in slow: $k_{-1}(A)=1000 \mathrm{~s}^{-1}, k_{-1}(B)=1 \mathrm{~s}^{-1}$ (U_R2_1.txt); (Fig. 5.f) the transition $A$ is in slow exchange, $B$-in fast: $k_{-1}(A)=1 \mathrm{~s}^{-1}, \mathrm{k}_{-1}(\mathrm{~B})=1000 \mathrm{~s}^{-1}$ (U_R2_2.txt).

U-RL model. $K_{a}(A)=10^{6} \mathrm{M}^{-1}, K_{i s o}(B)=5$; (Fig. 5.h) the transition $A$ is in slow exchange, $B$-in fast: $k_{-1}(A)=1 \mathrm{~s}^{-1}, \mathrm{k}_{-1}(B)=1000 \mathrm{~s}^{-1}$

(U_RL_2.txt); (Fig. 5.i) the transition $A$ is in fast exchange, $B$-in slow: $\mathrm{k}_{-1}(\mathrm{~A})=1000 \mathrm{~s}^{-1}, \mathrm{k}_{-1}(\mathrm{~B})=1 \mathrm{~s}^{-1}$ (U_RL_1.txt);

U-R2L2 model. $\mathrm{K}_{\mathrm{a}}(A)=10^{6} \mathrm{M}^{-1}, \mathrm{~K}_{\mathrm{a}}(\mathrm{B})=10^{4} \mathrm{M}^{-1}$; (Fig. 5.k) the transition $A$ is in slow exchange, $B$-in fast: $k_{-1}(A)=1 \mathrm{~s}^{-1}, k_{-1}(B)=1000$ $\mathrm{S}^{-1}$ (U_R2L2_2.txt); (Fig. 5.I) the transition $A$ is in fast exchange, $B$-in slow: $k_{-1}(A)=1000 \mathrm{~s}^{-1}, k_{-1}(B)=1 \mathrm{~s}^{-1}$ (U_R2L2_1.txt).

Fig. 6-Anomalous transient narrowing

The parameters for the simulations were as follows: (Panel $B$ ) U-R model, $\mathrm{K}_{\mathrm{a}}(\mathrm{A})=1.0 * 10^{6}, \mathrm{k}_{-1}(\mathrm{~A})=1000 \mathrm{~s}^{-1}, \mathrm{~K}_{\mathrm{a}}(\mathrm{B})=2, \mathrm{k}_{-1}(\mathrm{~B})=50 \mathrm{~s}^{-1}$; (Panel C) U-R2 model, $\mathrm{K}_{\mathrm{a}}(\mathrm{A})=1.0 * 10^{6}, \mathrm{k}_{-1}(\mathrm{~A})=1000 \mathrm{~s}^{-1}, \mathrm{~K}_{\mathrm{a}}(\mathrm{B})=$ $5.0 * 10^{4}, \mathrm{k}_{-1}(\mathrm{~B})=50 \mathrm{~s}^{-1}$; (Panel D) U-RL model, $\mathrm{K}_{\mathrm{a}}(\mathrm{A})=1.0^{*} 10^{6}, \mathrm{k}$ ${ }_{1}(A)=1000 \mathrm{~s}^{-1}, \mathrm{~K}_{\mathrm{a}}(\mathrm{B})=3, \mathrm{k}_{-1}(\mathrm{~B})=50 \mathrm{~s}^{-1}$. Full details of the simulations as well as parameter files to reproduce these results are given in Supplementary Information, 'Simulations/transient-narrowing'.

Acknowledgements: The author is deeply indebted to Dr. James Kempf for innumerable corrections, suggestions and comments, and Dr. Marius Clore for critical reading of the manuscript. The author acknowledges Dr. Mark Foster, Dr. Linda Nicholson, Dr. Brian Volkman, Casey O'Connor and Ian Kleckner for helpful discussions and practical comments. The author acknowledges Snehal Patil for creating the web interface for the LineShapeKin Simulation software and the Marquette University Committee on Research for financial support of web design (2012 Regular Research Grant).

Fig. 1. Effect of the exchange regime on NMR line shapes and peak shifts for the simplest $1: 1$ binding mechanism. Titrations in the fastintermediate exchange regime $\left(k_{\text {off }}=500 \mathrm{~s}^{-1}\right.$, Panel $\left.A\right)$ and slow-

Journal of Biomolecular NMR, Vol. 53, No. 3 (2012): pg. 257-270. DOI. This article is @ Springer and permission has been granted for this version to appear in e-Publications@Marquette. Springer does not grant permission for this article to be further copied/distributed or hosted elsewhere without the express permission from Springer. 
intermediate exchange regime ( $\mathrm{k}_{\text {off }}=200 \mathrm{~s}^{-1}$, Panel $\mathrm{C}$ ) are simulated as a function of consecutive additions of $L$. Resonance frequencies of $R$ and $\mathrm{RL}$ species are $0 \mathrm{~s}^{-1}$ and $300 \mathrm{~s}^{-1}$, indicated in the graphs with vertical lines. The association constant $\mathrm{K}_{\mathrm{a}}$ was set to $10^{5} \mathrm{M}^{-1}$. The receptor concentration is $1 \mathrm{mM}$ in this and all other simulations. The one-dimensional line shapes are simulated for a series of samples with $\mathrm{C}_{\mathrm{L}} / \mathrm{C}_{R}$ (the ratio of total amounts of ligand to receptor, $\mathrm{mol} / \mathrm{mol}$ ) ranging from 0 to 1.2 in steps of 0.1 . The $C_{L} / C_{R}$ value is indicated on the left of the graphs $A$ and $C$ next to the corresponding 1D traces. Red dots on each of the 1D traces locate the peak maxima. Panels $B$ and $D$ represent these positions as a function of corresponding titration progress in $\mathrm{A}$ and $\mathrm{C}$. A green straight line accompanies the curves to highlight the sigmoidal curvature of the plot in Panel D. The LineShapeKin Simulation setup files for this figure are given in the Supplementary Information, Simulation/fast_intermediate.

Fig. 2. Slow exchange line shapes for the $1: 1$ binding with different affinities. The line shapes are calculated with $k_{\text {off }}=20 \mathrm{~s}^{-1}$ for weak $\left(\mathrm{K}_{\mathrm{a}}\right.$ $=10^{5} \mathrm{M}^{-1}$, Panel $\left.\mathrm{A}\right)$ and tight binding $\left(\mathrm{K}_{\mathrm{a}}=10^{7} \mathrm{M}^{-1}\right.$, Panel $\left.\mathrm{C}\right)$, respectively. Resonance frequencies of $R$ and $R L$ species are $0 \mathrm{~s}^{-1}$ and $300 \mathrm{~s}^{-1}$. The $C_{L} / C_{R}$ value for each 1D trace is indicated on the left of the graphs $A$ and $C$. (Panels $B$ and $D$ ) The full width at the half height (FWHH) of the RL peak plotted as a function of the titration progress. The FWHH of the pure species were set to $20 \mathrm{~s}^{-1}$. To reproduce these results, use LineShapeKin Simulation setup files in the Supplementary Information, Simulation/slow_weak_tight.

Fig. 3. Basic three-state binding mechanisms with coupled equilibria. Bold labels U (for two-state), UR, U-RL, etc. (for three-state), indicate model names. In all cases, italicized $A$ and $B$ denote ligand-binding steps and coupled transitions, respectively.

Fig. 4. Three-state line shapes in fast exchange for two and threestate models and comparative analysis of their line-broadening patterns. (A-E) The line shapes were simulated for the following mechanisms: (A) U-model; (B) U-R; (C) U-R2; (D) U-RL; (E) U-R2L2. Markers at the top of each graph indicate frequencies of individual species. (F) Peak widths (full-width-at-half-height, FWHH) determined from simulated line shapes in $\mathbf{A}, \mathbf{B}, \mathbf{C}, \mathbf{D}$ and $\mathbf{E}$ are plotted as a

Journal of Biomolecular NMR, Vol. 53, No. 3 (2012): pg. 257-270. DOI. This article is @ Springer and permission has been granted for this version to appear in e-Publications@Marquette. Springer does not grant permission for this article to be further copied/distributed or hosted elsewhere without the express permission from Springer. 
function of the titration progress, $C_{L} / C_{R}$ (the model names are given in the legend). Connecting lines are to guide the eye only. All simulations assumed $K_{a}(A)=10^{6} \mathrm{M}^{-1}$, and $k_{-1}(A)=1000 \mathrm{~s}^{-1}$ for binding, and $K_{\text {iso }}(B)=$ 5 or $\mathrm{K}_{\mathrm{dim}}(\mathrm{B})=2.0 * 10^{4}$ for isomerization or dimerization transitions, respectively, either with $\mathrm{k}_{-1}(\mathrm{~B})=1000 \mathrm{~s}^{-1}$. The dimerization and isomerization constants were chosen to create population ratios in $\mathrm{B}$ processes on the order of 1:5. The frequencies at peak maxima and corresponding FWHH values were determined by numerical evaluation of the calculated spectral series. LineShapeKin Simulation setup files and full simulation results corresponding to these plots are included in Supplementary Information, 'Simulations/Fast_exchange_analysis'.

Fig. 5. Variations and ambiguity of NMR titration patterns from threestate mechanisms in mixed exchange regimes (opposite exchange regimes in the coupled processes $A$ and $B$ ). Each row of figures demonstrates results of simulations for the following three-state mechanisms: $(\mathbf{a}, \mathbf{b}, \mathbf{c})$ U-R, (d,e,f) U-R2, ( $\mathbf{g}, \mathbf{h}, \mathbf{i})$ U-RL, $(\mathbf{j}, \mathbf{k}, \mathbf{I})$ U-R2L2. The left-most graphs show evolution of populations during the titration. Dimeric species are represented as a corresponding fraction of a monomer population. The center and right-most graphs demonstrate simulated line shapes for the same titration when opposite exchange regimes are assumed (labeled as 'fast' and 'slow' above the corresponding transitions). The $C_{L} / C_{R}$ value for $1 \mathrm{D}$ traces is indicated on the left of the line shape traces and span the same range as the $C_{L} / C_{R}$ values in the population graph (from 0 to 1.2 with increments of 0.1 ). Frequencies of individual species are indicated for each line shape titration series by vertical dashed lines. The values of the equilibrium and rate constants as well as other parameters used for these simulations are provided in the Methods section.

Fig. 6. Anomalous transient narrowing due to mixed fast/intermediate exchange in the three-state systems. (Panel A) A reproduction of Figure 5C from (Mittag et al. 2004) (with appropriate permissions), which is a series of $1 \mathrm{D}$ slices from ${ }^{15} \mathrm{~N}-\mathrm{HSQC}$ spectrum of P395S N-SH2 domain as titrated with the PDGFr peptide. The titration progresses from the left-most peak to the right with the $C_{L} / C_{R}$ value incremented in 0.1 steps (blue to red). The spectral slice corresponding to $L / R=0.2$ is indicated with an inverted triangle at left, while the same marker at right indicates the peak of a fully saturated complex. [Note: The x-axis 
ordering of the original figure in the panel $A$ is reversed relative to an accepted NMR convention. All other plots of the current paper (including other panels in this figure) follow the accepted convention.] (Panel B) Qualitative reproduction of the 'anomalous' pattern in (Panel A) by the U-R model with ligand-binding occurring in fast exchange while the isomerization transition is in the intermediate exchange regime. Frequencies of individual species are indicated at top. The value of $C_{L} / C_{R}$ was incremented in steps of 0.1 , right-to-left as indicated in the figure. A similar 'transient narrowing' phenomenon predicted for the U-R2 (Panel $\mathbf{C}$ ) and U-RL (Panel D) models. The parameters used for all simulations are provided in the Methods section.

Fig. 7. Transient narrowing expected in the four-state (U-R-RL) systems in the mixed fast/intermediate exchange regime. (Panel $\mathbf{A}$ ) The scheme of the U-R-RL mechanism with isomerization of the free receptor and the bound complex such that $R^{*}$ and $(R L) * *$ species cannot directly interconvert through ligand binding/dissociation. (Panel B) Simulated line shapes for a titration of $U-R-R L$ mechanism with disconnected $R^{*}$ and $(R L) * *$. The simulation parameters were $K_{a}\left(A_{1}\right)=$ $1.0 * 10^{6}, \mathrm{~K}_{\mathrm{a}}\left(\mathrm{B}_{1}\right)=1.1$, and $\mathrm{K}_{\mathrm{a}}\left(\mathrm{B}_{2}\right)=1.1$. Kinetic rate constants were $\mathrm{k}$ ${ }_{1}\left(A_{1}\right)=3000 \mathrm{~s}^{-1}, \mathrm{k}_{-1}\left(A_{2}\right)=0 \mathrm{~s}^{-1}, \mathrm{k}_{-1}\left(B_{1}\right)=80 \mathrm{~s}^{-1}, \mathrm{k}_{-1}\left(B_{2}\right)=80 \mathrm{~s}^{-1}$. Setting of $\mathrm{k}_{-1}\left(\mathrm{~A}_{2}\right)$ to zero ensures that $\mathrm{R}^{*}$ and $(\mathrm{RL}) * *$ cannot interconvert. Frequencies of individual species are indicated in the figure. Ratio of $L$ to $\mathrm{R}(\mathrm{mol} / \mathrm{mol})$ was incremented in 0.1 steps and is indicated in the figure. (Panel $\mathbf{C}$ ) The scheme of the U-R-RL mechanism where $\mathrm{R}^{*}$ and $R^{*} \mathrm{~L}$ species are directly linked via binding/dissociation of $\mathrm{L}$. (Panel $\mathbf{D}$ ) Simulated line shapes for a titration of the U-R-RL mechanism with connected $R^{*}$ and $R * L$. To enable their direct interconversion the value of the off-rate constant $\mathrm{k}_{-1}\left(\mathrm{~A}_{2}\right)$ was set to $3000 \mathrm{~s}^{-1}$. The fourth equilibrium constant, for the $A 2$ binding transition, is linked to the other three as $\mathrm{K}_{\mathrm{A} 2}=\mathrm{K}_{\mathrm{A} 1} \mathrm{~K}_{\mathrm{B} 2} / \mathrm{K}_{\mathrm{B} 1}$ through the thermodynamic cycle. Full details of the simulations are given in Supplementary Information, 'Simulations/transientnarrowing/

U_R_RL' and '-/U_R_RL_2'.

\section{References}

Abraham A (1983) Principles of Nuclear Magnetism. International Series of Monographs on Physics. Oxford University Press, USA,

Journal of Biomolecular NMR, Vol. 53, No. 3 (2012): pg. 257-270. DOI. This article is @ Springer and permission has been granted for this version to appear in e-Publications@Marquette. Springer does not grant permission for this article to be further copied/distributed or hosted elsewhere without the express permission from Springer. 
NOT THE PUBLISHED VERSION; this is the author's final, peer-reviewed manuscript. The published version may be

accessed by following the link in the citation at the bottom of the page.

Bain AD, Duns GJ (1996) A unified approach to dynamic NMR based on a physical interpretation of the transition probability. Can J Chem 74:819-824

Boehr DD, Nussinov R, Wright PE (2009) The role of dynamic conformational ensembles in biomolecular recognition. Nat Chem Biol 5 (11):789-796

Cavanaugh J, Fairbrother WJ, Palmer III AG, Skelton NJ (2006) Protein NMR Spectroscopy: Principles and Practice. Academic Press,

Cogliati C, Ragona L, D'Onofrio M, Gunther U, Whittaker S, Ludwig C, Tomaselli S, Assfalg M, Molinari H (2010) Site-Specific Investigation of the Steady-State Kinetics and Dynamics of the Multistep Binding of Bile Acid Molecules to a Lipid Carrier Protein. Chemistry-a European Journal 16 (37):11300-11310. doi:10.1002/chem.201000498

Csermely P, Palotai R, Nussinov R (2010) Induced fit, conformational selection and independent dynamic segments: an extended view of binding events. Trends in Biochemical Sciences 35 (10):539-546

Demers JP, Mittermaier A (2009) Binding mechanism of an SH3 domain studied by NMR and ITC. J Am Chem Soc 131 (12):4355-4367. doi:10.1021/ja808255d

Farber P, Darmawan H, Sprules T, Mittermaier A (2010) Analyzing Protein Folding Cooperativity by Differential Scanning Calorimetry and NMR Spectroscopy. Journal of the American Chemical Society 132 (17):6214-6222. doi:10.1021/ja100815a

Farrow NA, Zhang O, Forman-Kay JD, Kay LE (1994) A heteronuclear correlation experiment for simultaneous determination of $15 \mathrm{~N}$ longitudinal decay and chemical exchange rates of systems in slow equilibrium. Journal of Biomolecular NMR 4 (5):727-734

Feeney J, Batchelor JG, Albrand JP, Roberts GCK (1979) The effects of intermediate exchange processes on the estimation of equilibrium constants by NMR. J Magn Reson 33:519

Fischer E (1894) Einfluss der Configuration auf die Wirkung der Enzyme (Influence of Configuration on the Effect of Enzymes). Ber Dtsch Chem Ges 27:2984-2993

Gabrielson JP, Arthur KK (2011) Measuring low levels of protein aggregation by sedimentation velocity. Methods 54 (1):83-91. doi:10.1016/j.ymeth.2010.12.030

Greenwood A, Rogals M, De S, Lu K, Kovrigin E, Nicholson L (2011) Complete determination of the Pin1 catalytic domain thermodynamic cycle by NMR lineshape analysis. Journal of Biomolecular Nmr 51 (1):21-34. doi: 10.1007/s10858-011-9538-9

Grey MJ, Wang C, Palmer AG (2003) Disulfide Bond Isomerization in Basic Pancreatic Trypsin Inhibitor: Multisite Chemical Exchange Quantified by CPMG Relaxation Dispersion and Chemical Shift Modeling. Journal of

Journal of Biomolecular NMR, Vol. 53, No. 3 (2012): pg. 257-270. DOI. This article is @ Springer and permission has been granted for this version to appear in e-Publications@Marquette. Springer does not grant permission for this article to be further copied/distributed or hosted elsewhere without the express permission from Springer. 
NOT THE PUBLISHED VERSION; this is the author's final, peer-reviewed manuscript. The published version may be accessed by following the link in the citation at the bottom of the page.

the American Chemical Society 125 (47):14324-14335. doi:10.1021/ja0367389

Gunasekaran K, Ma B, Nussinov R (2004) Is allostery an intrinsic property of all dynamic proteins? Proteins 57 (3):433 - 443

Gunther UL, Mittag T, Schaffhausen B (2002) Probing Src homology 2 domain ligand interactions by differential line broadening. Biochemistry 41 (39): 11658-11669

Günther UL, Schaffhausen B (2002) NMRKIN: Simulating line shapes from two-dimensional spectra of proteins upon ligand binding. Journal of Biomolecular NMR 22 (3):201-209

Haugh JM, Elston TC, Cirit M, Wang C-C, Hao N, Yildirim N (2009) Datadriven, mechanistic modeling of biochemical reaction networks. In: Methods in Bioengineering: Systems Analysis of Biological Networks. Artech House, pp 57-74

Henkels CH, Kurz JC, Fierke CA, Oas TG (2001) Linked folding and anion binding of the Bacillus subtilis ribonuclease $P$ protein. Biochemistry 40 (9):2777-2789

Kaplan JI, Fraenkel G (1980) NMR of Chemically Exchanging Systems. Academic Press,

Kay LE (2005) NMR studies of protein structure and dynamics. Journal of Magnetic Resonance 173 (2):193-207

Kempf JG, Jung J-Y, Ragain C, Sampson NS, Loria JP (2007) Dynamic Requirements for a Functional Protein Hinge. J Mol Biol 368:131-149

Kern D, Kern G, Scherer G, Fischer G, Drakenberg T (1995) Kinetic analysis of cyclophilin-catalyzed prolyl cis/trans isomerization by dynamic NMR spectroscopy. Biochemistry 34 (41):13594-13602

Korzhnev DM, Bezsonova I, Lee S, Chalikian TV, Kay LE (2009) Alternate binding modes for a ubiquitin-SH3 domain interaction studied by NMR spectroscopy. J Mol Biol 386 (2):391-405

Koshland DE (1958) Application of a theory of enzyme specificity to protein synthesis. Proc Natl Acad Sci U S A 44:98-104

Koshland DE (1994) The key-lock theory and the induced fit theory. Angewandte Chemie International Edition Engl 33:2375-2378

Kovrigin EL, Loria JP (2006) Enzyme dynamics along the reaction coordinate: Critical role of a conserved residue. Biochemistry 45 (8):2636-2647

Kumar S, Ma BY, Tsai CJ, Sinha N, Nussinov R (2000) Folding and binding cascades: Dynamic landscapes and population shifts. Protein Science 9 (1): $10-19$

Ma B, Nussinov R (2010) Enzyme dynamics point to stepwise conformational selection in catalysis. Current Opinion in Chemical Biology 14 (5):652659

Journal of Biomolecular NMR, Vol. 53, No. 3 (2012): pg. 257-270. DOI. This article is @ Springer and permission has been granted for this version to appear in e-Publications@Marquette. Springer does not grant permission for this article to be further copied/distributed or hosted elsewhere without the express permission from Springer. 
NOT THE PUBLISHED VERSION; this is the author's final, peer-reviewed manuscript. The published version may be

accessed by following the link in the citation at the bottom of the page.

Markley JL (1975) Observation of Histidine Residues in Proteins by Means of Nuclear Magnetic Resonance Spectroscopy. Accounts of Chemical Research 8:70

McConnell H (1958) Reaction rates by nuclear magnetic resonance. J Chem Phys 28:430-431

Mittag T, Schaffhausen B, Gunther UL (2003) Direct observation of proteinligand interaction kinetics. Biochemistry 42 (38):11128-11136

Mittag T, Schaffhausen B, Gunther UL (2004) Tracing kinetic intermediates during ligand binding. Journal of the American Chemical Society 126 (29): 9017-9023

Mogilner A, Wollman R, Marshall WF (2006) Quantitative modeling in cell biology: What is it good for? Developmental Cell 11 (3):279-287. doi:10.1016/j.devcel.2006.08.004

Monod J, Wyman J, Changeux JP (1965) On the Nature of Allosteric Transitions: a Plausible Model. J Mol Biol 12:88-118

Ortega A, Amoros D, de la Torre JG (2011) Global fit and structure optimization of flexible and rigid macromolecules and nanoparticles from analytical ultracentrifugation and other dilute solution properties. Methods 54 (1):115-123. doi:10.1016/j.ymeth.2010.12.004

Palmer AG, Kroenke CD, Loria JP (2001) Nuclear magnetic resonance methods for quantifying microsecond-to-millisecond motions in biological macromolecules. Methods in Enzymology 339:204-238

Rao BDN (1989) Nuclear magnetic resonance line-shape analysis and determination of exchange rates. In: Methods in Enzymology. Volume 176 edn. Academic Press, pp 279-311

Royer CA, Scarlata SF (2008) Fluorescence approaches to quantifying biomolecular interactions. Methods Enzymol 450:79-106. doi:10.1016/S0076-6879(08)03405-8

Shepherd TR, Fuentes EJ (2011) Structural and thermodynamic analysis of PDZ-ligand interactions. Methods Enzymol 488:81-100. doi: 10.1016/B978-0-12-381268-1.00004-5

Sudmeier JL, Evelhoch JL, Jonsson NBH (1980) Dependence of NMR lineshape analysis upon chemical rates and mechanisms: Implications for enzyme histidine titrations. Journal of Magnetic Resonance (1969) 40 (2):377-390

Sugase K, Dyson HJ, Wright PE (2007a) Mechanism of coupled folding and binding of an intrinsically disordered protein. Nature 447:1021-1025

Sugase K, Lansing JC, Dyson HJ, Wright PE (2007b) Tailoring Relaxation Dispersion Experiments for Fast-Associating Protein Complexes. Journal of the American Chemical Society 129 (44):13406-13407. doi: $10.1021 / \mathrm{ja} 0762238$

Swain JF, Gierasch LM (2006) The changing landscape of protein allostery. Current Opinion in Structural Biology 16 (1):102-108

Journal of Biomolecular NMR, Vol. 53, No. 3 (2012): pg. 257-270. DOI. This article is @ Springer and permission has been granted for this version to appear in e-Publications@Marquette. Springer does not grant permission for this article to be further copied/distributed or hosted elsewhere without the express permission from Springer. 
Tsai CJ, del Sol A, Nussinov R (2008) Allostery: absence of a change in shape does not imply that allostery is not at play. J Mol Biol 378 (1):1-11. doi:S0022-2836(08)00231-3 [pii]

\section{Figure 1}
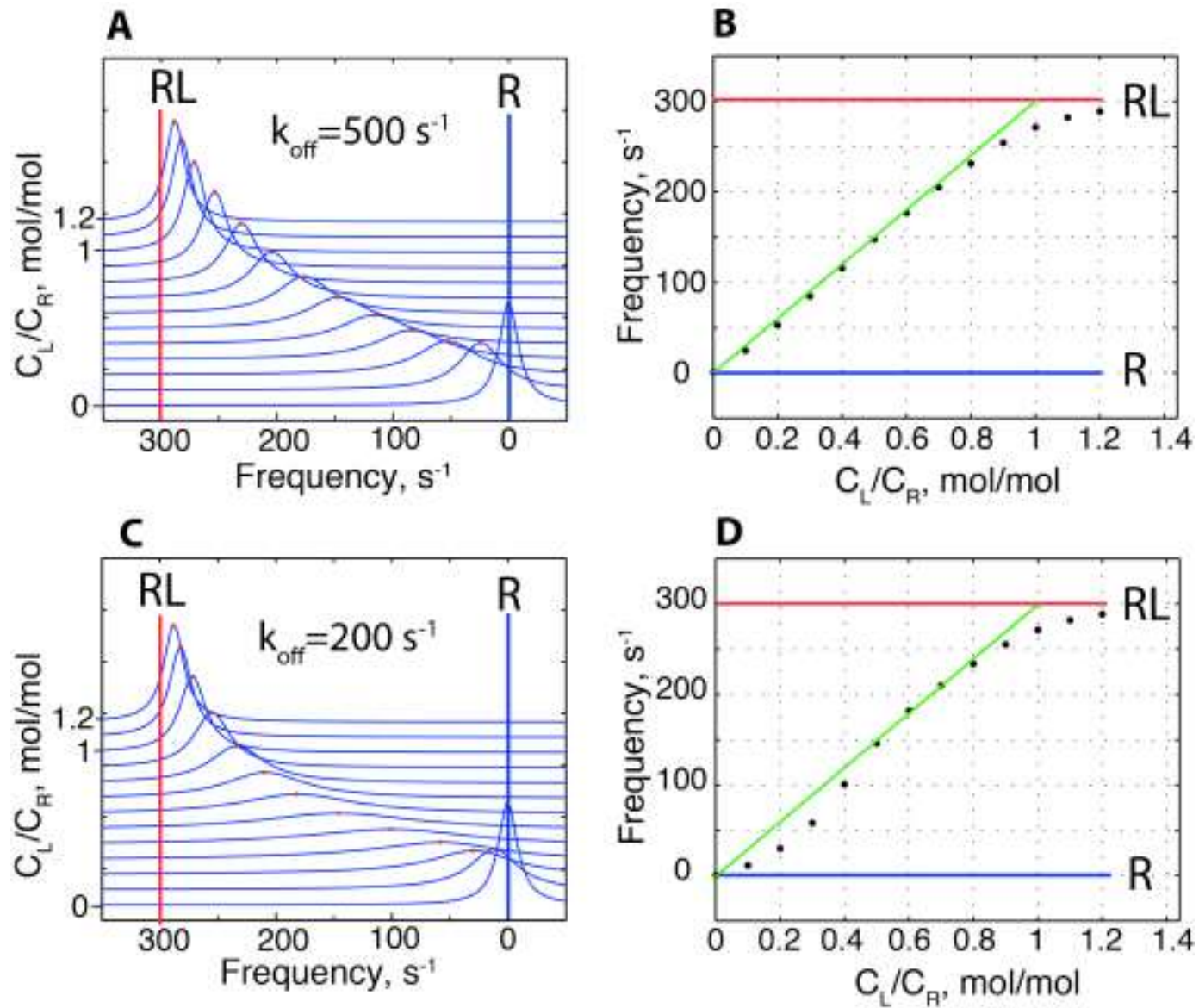

Journal of Biomolecular NMR, Vol. 53, No. 3 (2012): pg. 257-270. DOI. This article is @ Springer and permission has been granted for this version to appear in e-Publications@Marquette. Springer does not grant permission for this article to be further copied/distributed or hosted elsewhere without the express permission from Springer. 
NOT THE PUBLISHED VERSION; this is the author's final, peer-reviewed manuscript. The published version may be accessed by following the link in the citation at the bottom of the page.

Figure 2

A
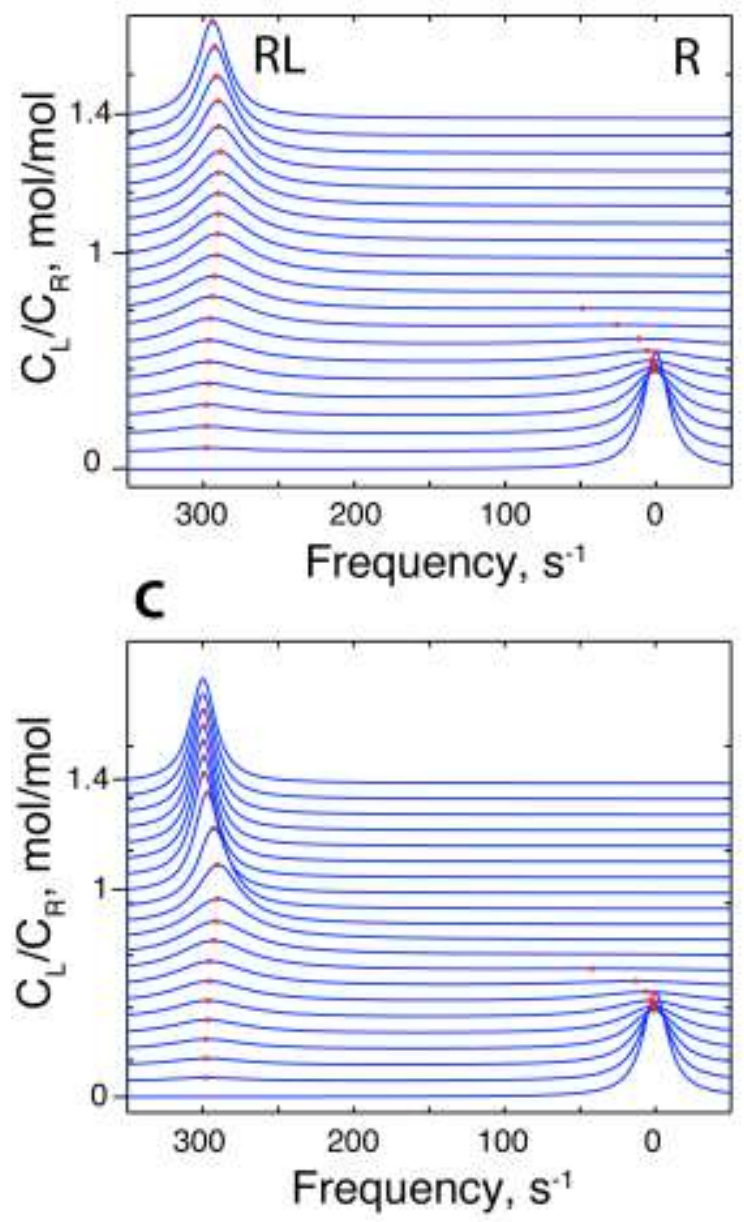

B

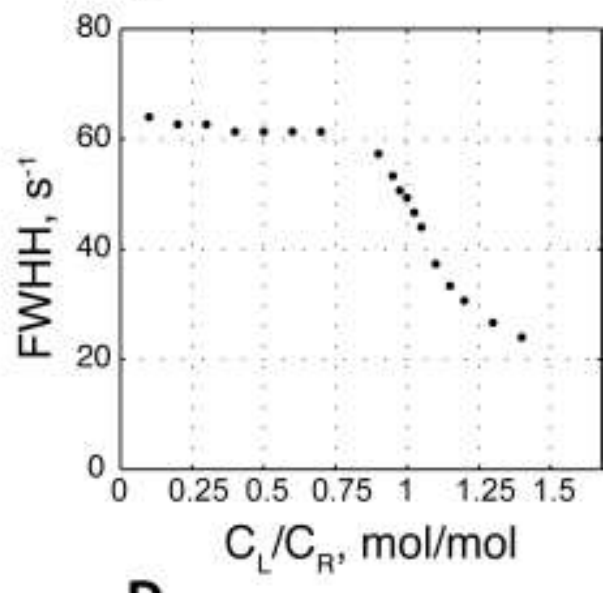

D

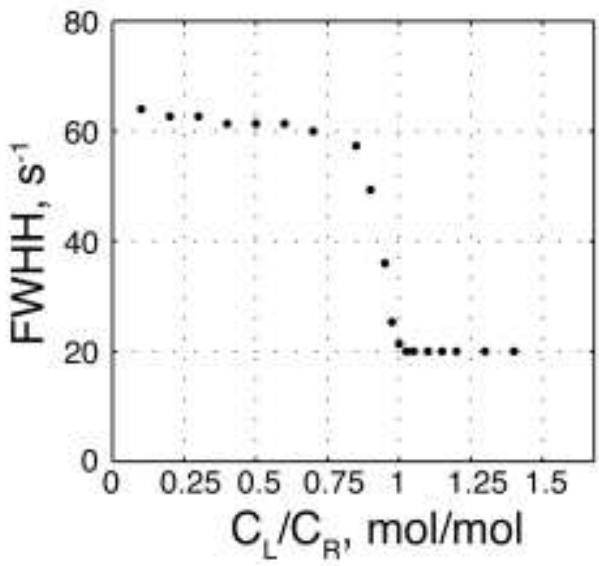

Figure 3

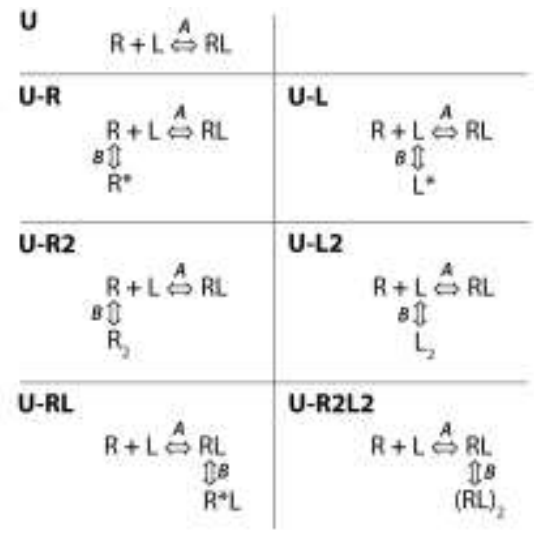

Journal of Biomolecular NMR, Vol. 53, No. 3 (2012): pg. 257-270. DOI. This article is C Springer and permission has been granted for this version to appear in e-Publications@Marquette. Springer does not grant permission for this article to be further copied/distributed or hosted elsewhere without the express permission from Springer. 
NOT THE PUBLISHED VERSION; this is the author's final, peer-reviewed manuscript. The published version may be accessed by following the link in the citation at the bottom of the page.

Figure 4
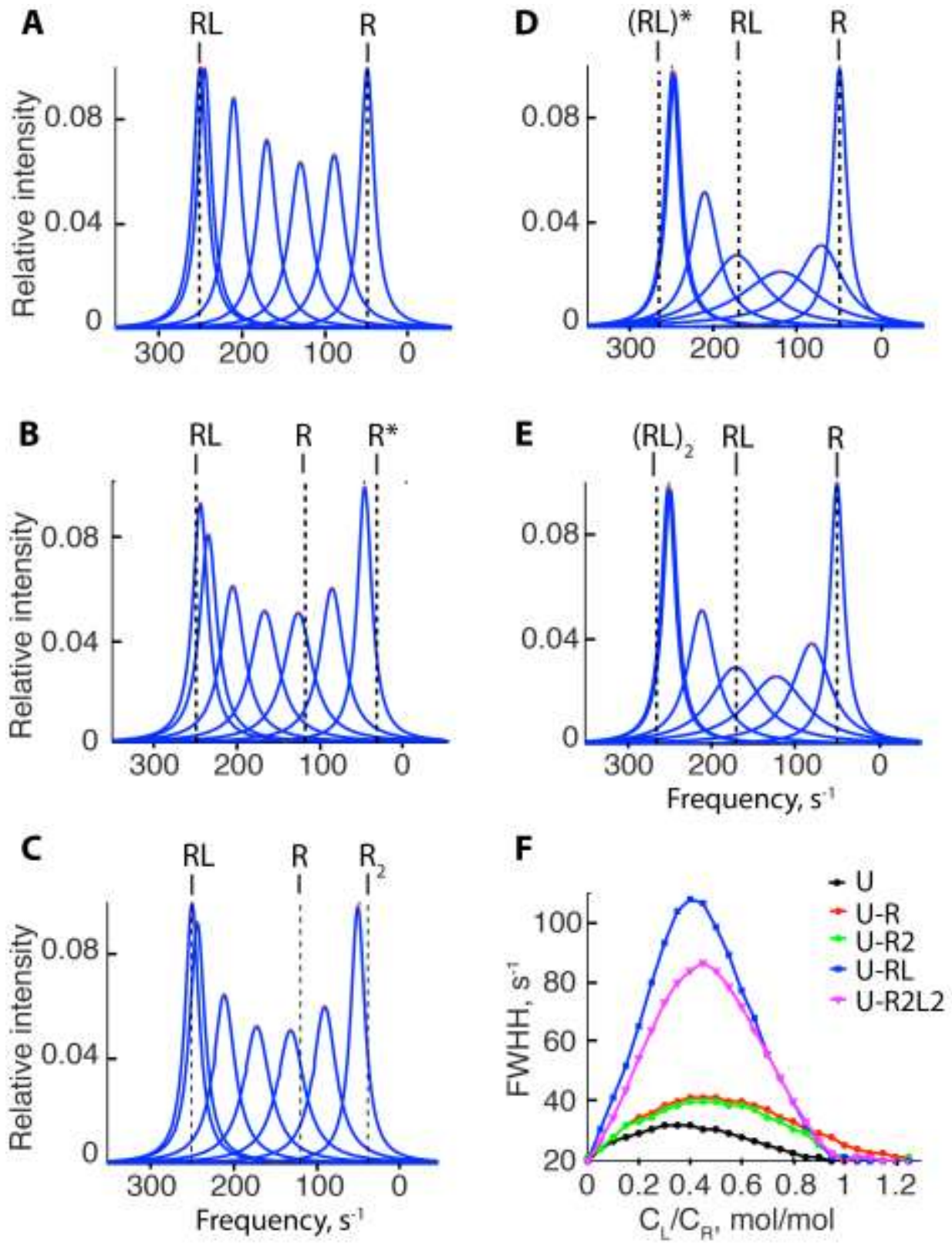

Journal of Biomolecular NMR, Vol. 53, No. 3 (2012): pg. 257-270. DOI. This article is @ Springer and permission has been granted for this version to appear in e-Publications@Marquette. Springer does not grant permission for this article to be further copied/distributed or hosted elsewhere without the express permission from Springer. 
NOT THE PUBLISHED VERSION; this is the author's final, peer-reviewed manuscript. The published version may be accessed by following the link in the citation at the bottom of the page.

Figure 5
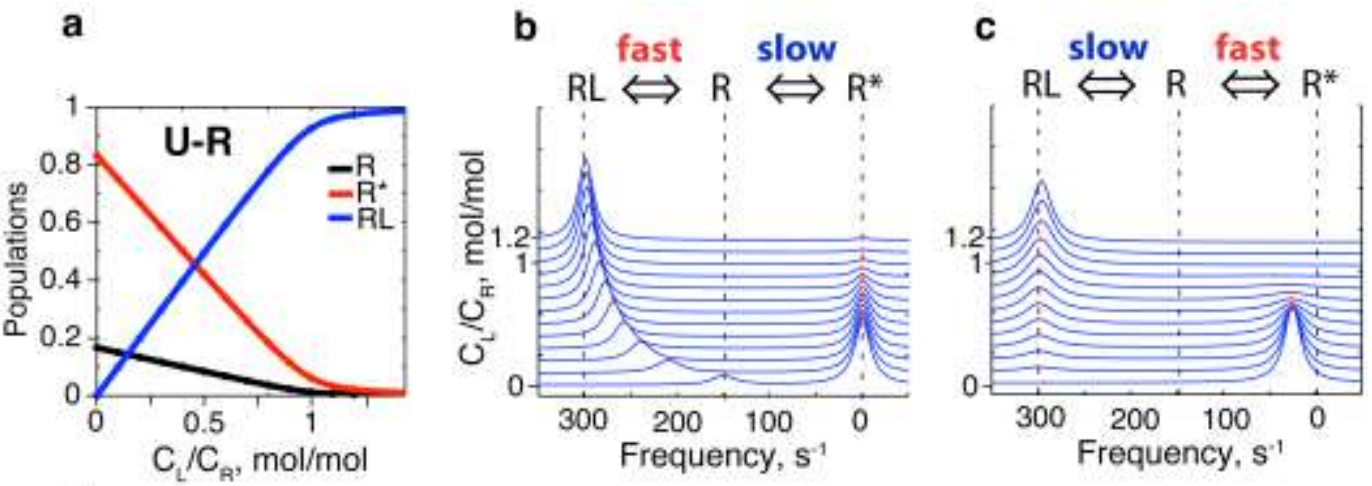

\section{d}
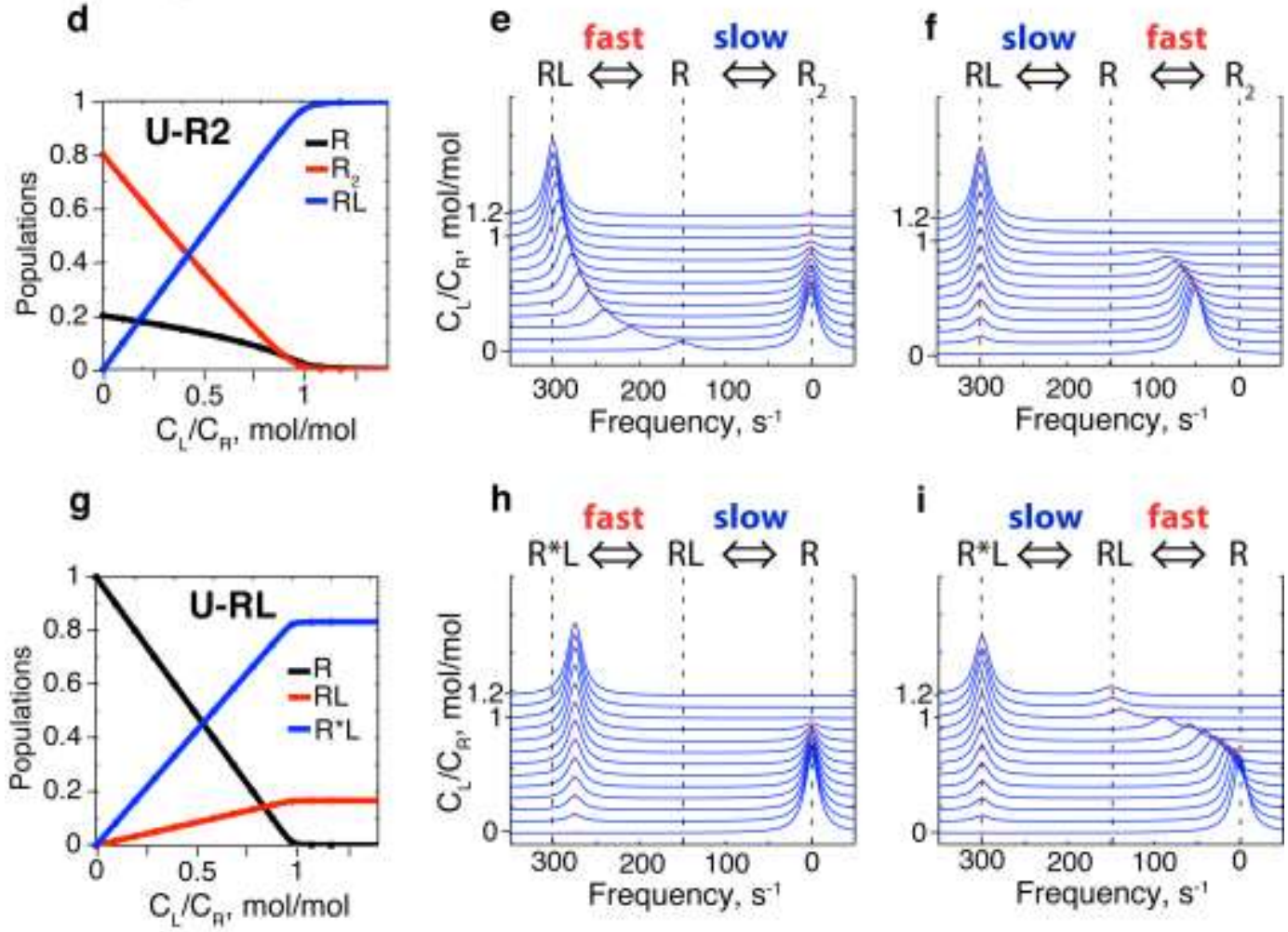

i slow fast
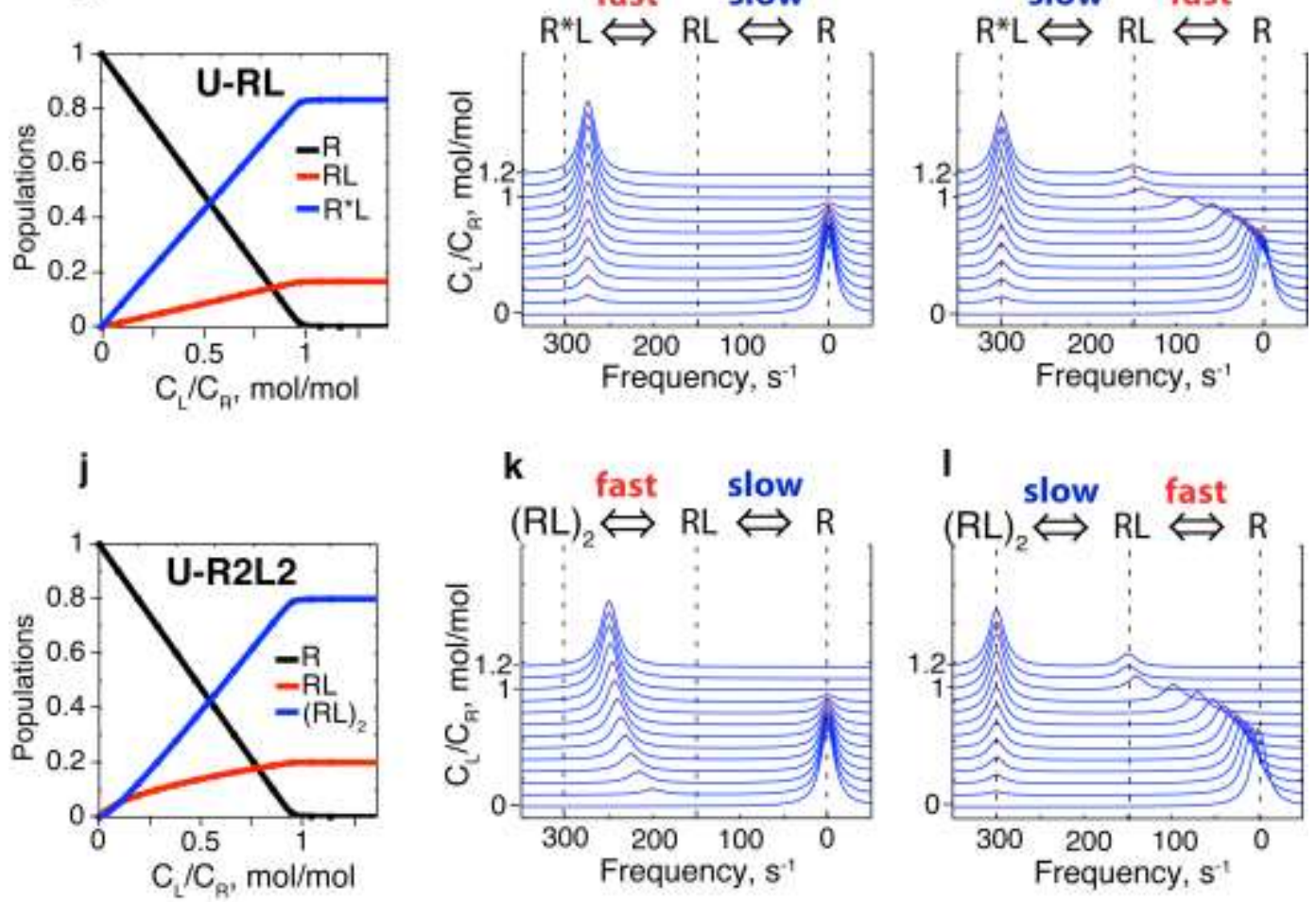

Journal of Biomolecular NMR, Vol. 53, No. 3 (2012): pg. 257-270. DOI. This article is @ Springer and permission has been granted for this version to appear in e-Publications@Marquette. Springer does not grant permission for this article to be further copied/distributed or hosted elsewhere without the express permission from Springer. 
NOT THE PUBLISHED VERSION; this is the author's final, peer-reviewed manuscript. The published version may be accessed by following the link in the citation at the bottom of the page.

Figure 6
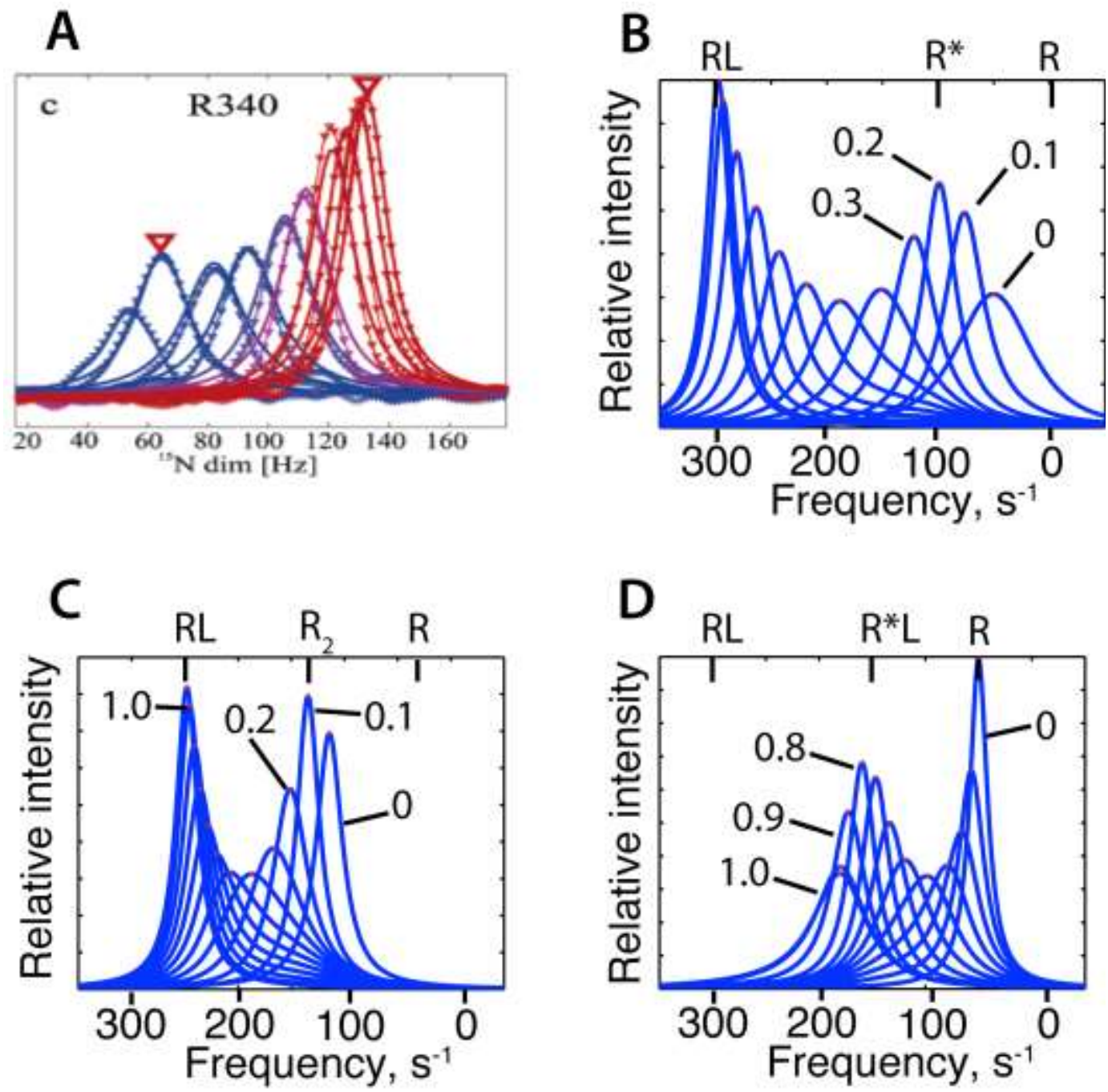

Journal of Biomolecular NMR, Vol. 53, No. 3 (2012): pg. 257-270. DOI. This article is @ Springer and permission has been granted for this version to appear in e-Publications@Marquette. Springer does not grant permission for this article to be further copied/distributed or hosted elsewhere without the express permission from Springer. 
Figure 7

A
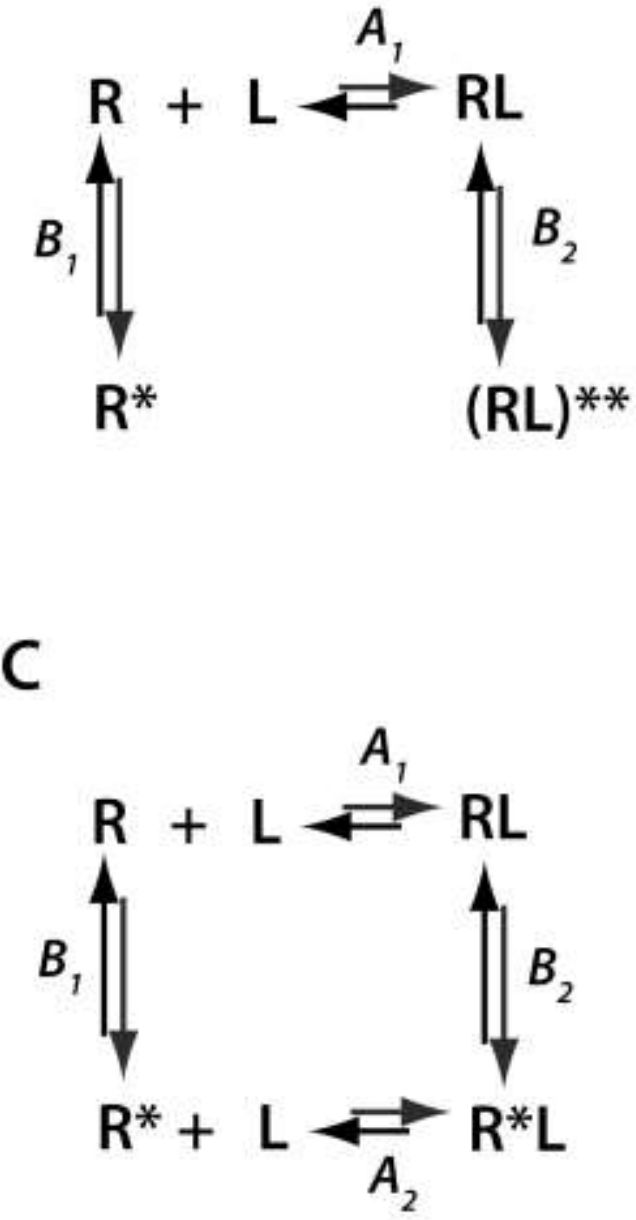
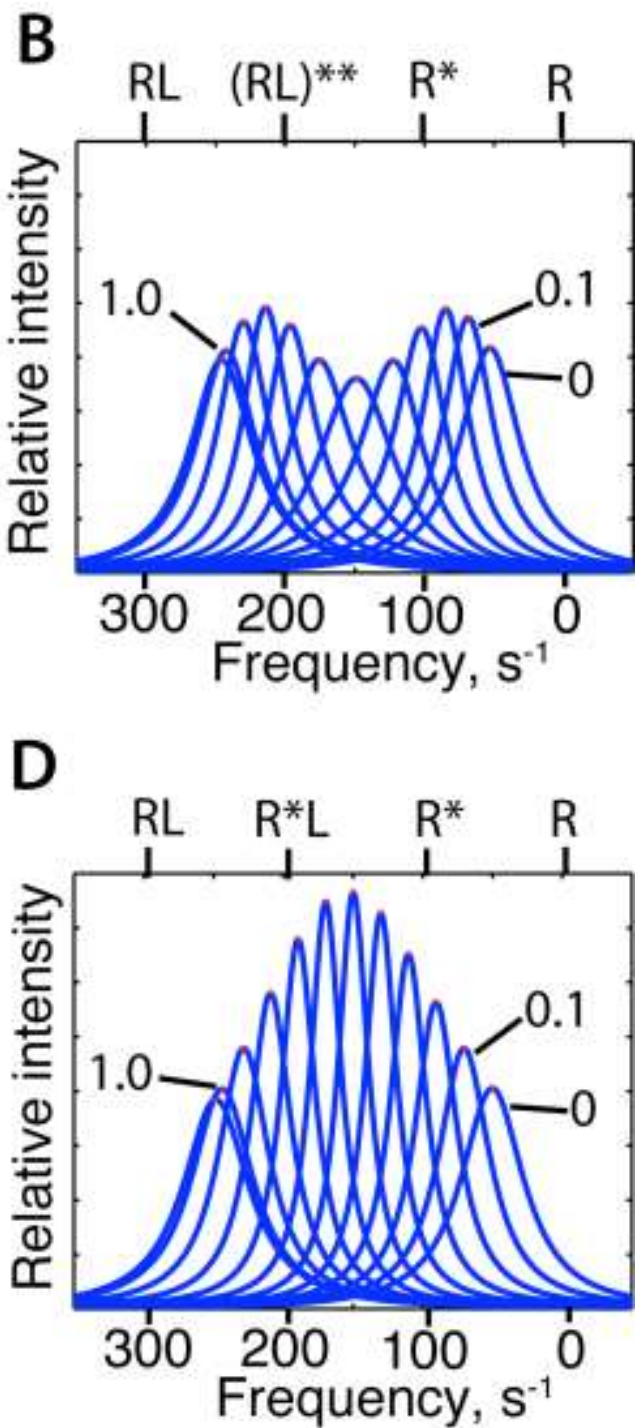

\section{Notes:}

${ }^{1}$ Briefly, an exchanging system is in the fast-exchange regime when the exchange rate constant $(k \mathrm{ex})$ is much larger than a difference between the resonance frequencies of exchanging species (sites): $k$ ex $\gg \Delta \omega$. In fast exchange, a single resonance is observed at a frequency equal to the population-weighted average of frequencies of individual species (Kaplan and Fraenkel 1980). The condition of $k_{e x} \ll \Delta \omega$ corresponds to a slow-exchange regime, manifested by appearance of separate resonances for individual species with peak areas (volumes) proportional to their equilibrium 
NOT THE PUBLISHED VERSION; this is the author's final, peer-reviewed manuscript. The published version may be accessed by following the link in the citation at the bottom of the page.

populations. Intermediate exchange is when $k_{e x} \approx \Delta \omega$ and results in very significant broadening of the resonances and non-Lorentzian line shapes. For convenience, we also refer to the "fast-intermediate" (or "slowintermediate") exchange regime to specify situations when $k$ ex is larger (smaller) than $\Delta \omega$ but not to such extent that purely fast or slow behavior holds.

${ }^{2}$ To facilitate comparative analysis, the frequency of the "intermediate" species in the three-state mechanisms is always placed in between the frequencies of the "end" species in all simulations for Fig. 5 (i.e. the frequency of $\mathrm{R}$ is in between of $\mathrm{R}^{*}$ and $\mathrm{RL}$, etc.). Additional simulations established that alternative relative placement of frequencies for the three species does not produce qualitatively new results.

${ }^{3}$ For $\mathrm{U}-\mathrm{R}$, the ratio of $\mathrm{R}$ to $\mathrm{R} *$ is constant throughout the titration because the unimolecular isomerization is independent of the receptor concentration. 